\title{
Strengthening networks: A social network intervention among higher education teachers
}

\author{
Sara Van Waes ${ }^{\mathrm{a},}{ }^{*}$, Sven De Maeyer ${ }^{\mathrm{b}}$, Nienke M. Moolenaar ${ }^{\mathrm{c}}$, Peter Van Petegem ${ }^{\mathrm{b}}$, \\ Piet Van den Bossche ${ }^{\mathrm{b}, \mathrm{d}}$ \\ a Antwerp School of Education, Center for Excellence in Higher Education, University of Antwerp, Venusstraat 35, 2000 Antwerp, Belgium \\ ${ }^{\mathrm{b}}$ Department of Training and Education, Faculty of Social Sciences, University of Antwerp, Venusstraat 35, 2000 Antwerp, Belgium \\ ${ }^{\mathrm{c}}$ Department of Education, Utrecht University, Heidelberglaan 1, P.O. Box 80.140, 3508 TC Utrecht, The Netherlands \\ ${ }^{\mathrm{d}}$ Educational Research and Development, Maastricht University, P.O. Box 616, 6200 MD Maastricht, The Netherlands
}

\section{A R T I C L E I N F O}

\section{Article history:}

Received 1 September 2016

Received in revised form

14 May 2017

Accepted 7 July 2017

Available online 28 July 2017

\section{Keywords:}

Social network

Professional development

Network intervention

Higher education

Academic development

\begin{abstract}
A B S T R A C T
Teachers' opportunities to learn at the workplace are shaped by the relationships in which they discuss their instructional practice, what we call teaching networks. This study examined the extent to which such teaching networks could be strengthened during a professional development (PD) program. An intervention was designed to evaluate whether the development of teaching networks was affected in terms of network composition and access to teaching content. Longitudinal ego-network data of Belgian university teachers $(\mathrm{N}=38,1670$ ties) were collected over a two-year time period. Multilevel analyses showed that the intervention group developed larger networks and increased network dynamics, compared to the control group. The intervention group also developed more diverse networks, and showed increased access to teaching content, suggesting that the intervention changed teachers' networks over time. This study shows the potential of network interventions to support teachers' professional development, and of network analysis as a tool to analyze professional relations.
\end{abstract}

() 2017 Elsevier Ltd. All rights reserved.

\section{Introduction}

Traditionally, calls for professional development of teachers have been answered with formal training initiatives (Avalos, 2011; Saroyan \& Trigwell, 2015), i.e. structurally organized professional development (PD) programs aimed at enhancing teaching and learning. Yet, across the globe, informal learning is increasingly recognized as an important driver for ongoing professional development (Kyndt, Gijbels, Grosemans, \& Donche, 2016) as most learning within the teaching profession takes place through collegial interaction and transcends boundaries of formal programs (Lieberman \& Pointer Mace, 2008; Vangrieken, Dochy, Raes, \& Kyndt, 2015). The current body of research on PD programs mainly focuses on the knowledge and skills of individual teachers. Scholars increasingly suggest to complement this research with a

\footnotetext{
* Corresponding author.

E-mail addresses: Sara.VanWaes@uantwerpen.be (S. Van Waes), Sven. DeMaeyer@uantwerpen.be (S. De Maeyer), N.M.Moolenaar@uu.nl (N.M. Moolenaar), Peter.VanPetegem@uantwerpen.be (P. Van Petegem), Piet. VandenBossche@uantwerpen.be (P. Van den Bossche).
}

focus on teachers' networks, aimed at enhancing teachers' access to resources through social relationships (A. Fox \& Wilson, 2015; Penuel, Sun, Frank, \& Gallagher, 2012). Recently, emerging research highlights the importance of the personal teaching networks that surround participants during PD programs (Van Waes, Van den Bossche, Moolenaar, Stes, \& Van Petegem, 2015b; Rienties \& Kinchin, 2014). These scholars have suggested that for PD programs to be effective and sustainable, participants have to learn to recognize and access their network. However, most research is limited to descriptive accounts of networks and little is known about if and how teachers can strengthen their networks.

Given this gap, the central aim of this study is to examine the extent to which teaching networks can be strengthened during PD programs. In specific, we focus on academics who teach at the university. For this set of teachers, informal learning is of particular importance as university teachers traditionally begin teaching in higher education with little or no formal training. Being an expert in the content field is assumed to be a sufficient condition to teach others (Denicolo \& Becker, 2013). Over the past two decades, improving university teaching standards has been the driver of interest in academic development internationally (Baume, 2006; 
Devlin \& Samarawickrema, 2010). Isolated practice is considered an inadequate way of performing teachers' work (Bakkenes, De Brabander, \& Imants, 1999). Yet, issues of privacy, autonomy, and even isolation in higher education have been quite prominent (Cox, 2004; Ramsden, 1998).

This study draws on research on performance, expertise development and on social network research to explore the role of networks in supporting professional development, and more specifically, the potential of network interventions for university teachers' professional development.

\subsection{A network perspective on professional development}

Studies on workplace learning of professionals are increasingly taking a social perspective on development to understand its relational and interactive nature (Gruber, Lehtinen, Palonen, \& Degner, 2008; Tynjälä, 2008). The urge to capitalize on social interaction is reflected by a growing number of concepts that aim to improve this social side of learning, such as communities of practice, professional communities, and networks (Louis \& Marks, 1998; McLaughlin \& Talbert, 2006; Wenger, McDermott, \& Snyder, 2002). In education, the development of teachers is no longer regarded as an individual endeavor, rather, it is placed within the larger network of relationships that surrounds the individual (Moolenaar, 2012). Social network theory provides a valuable lens and the tools to examine professional interactions of teachers (Carolan, 2014). The key assumption of social network theory is that individuals' behavior and performance are significantly affected by the way that they are tied into a larger web of social connections (Burt, 1992; Granovetter, 1973). Interest in teachers' professional interactions has sparked an important body of research into the meaning and potential of networks. This research has established the significance of teaching networks for student achievement (Pil \& Leana, 2009), teacher development (Van Waes, Van den Bossche, Moolenaar, De Maeyer, \& Van Petegem, 2015a; Van Waes et al., 2016), reform and improvement (Daly \& Finnigan, 2011), policy implementation (Coburn \& Russell, 2008), and leadership (Pitts \& Spillane, 2009).

\subsection{Teaching networks in professional development (PD) programs}

The recognition of the importance of networks for professional development, affects our thinking around PD programs. Up until now, teacher interaction during PD programs has mostly been reported as a side-effect while studying PD programs from a mainly individual perspective (Postareff, Lindblom-Ylänne, \& Nevgi, 2007; Stes, Clement, \& Van Petegem, 2007). Recently, a small body of research emerged using a social network perspective to study the extent to which teachers actually engage in interactions around their teaching practice during and beyond PD programs. Findings showed that within PD programs, teachers' connections with other participants increased over time (Moses, Heestand Skinner, Hicks, \& O'Sullivan, 2009; Rienties \& Kinchin, 2014). Furthermore, teachers also increasingly engaged in collegial interaction outside the PD program, with colleagues in the department or grade (Van Waes et al., 2015b; Gamoran, Gunter, \& Williams, 2005). These connections are considered valuable since teachers' approaches to teaching can be shaped by the perceptions of the cultures into which they are inserted (Roxå \& Mårtensson, 2009; Spillane, Kim, \& Frank, 2012). However, PD programs do not automatically influence the networks of every teacher involved. In specific, a recent longitudinal study on network development in PD programs showed that while on average, networks changed significantly, this study also discerned different profiles of network change (stable, flexible, expansive, isolated) showing some university teachers that did not change their networks during the program, nor connected with others about their teaching practice (Van Waes et al., 2015b).

\subsection{Interventions to strengthen networks}

Scholars are increasingly suggesting that for PD programs to be effective and sustainable, participants have to learn to recognize and access their personal teaching network (Baker-Doyle \& Yoon, 2010; Penuel et al., 2012). Some studies contain suggestions for further research on how to promote or support network development in PD programs, e.g. assisting participants in recognizing the potential of collegial interactions, implementing critical friend systems and peer observations, or involving colleagues from the workplace (Gerken, Beausaert, \& Segers, 2016; Thomson, 2015). Yet, to our knowledge, the current body of work provides little empirical insight into the extent to which teaching networks can actually be strengthened.

Recently, network interventions have been developed to support professionals and organizations to intentionally act on their networks (Cross \& Thomas, 2009; Parise, 2007). Network interventions are purposeful efforts to use social network data to accelerate behavior change, to improve performance, or diffuse innovations (Valente, 2012). Valente (2012) presents four strategies to use network data for intervention: (i) identifying individuals (e.g., key players or opinion leaders) for diffusion purposes: (ii) segmentation to identify groups of people to change at the same time; (iii) induction to create cascades of information diffusion (e.g., word of mouth, respondent-driven sampling); and (iv) alterations that change the network. These interventions often build on the underlying assumption that individuals, who are aware of their networks and the resources and expertise residing in it, are more likely to reach out to the 'right' people at the 'right' time when presented with challenges or opportunities (Borgatti \& Cross, 2003). Teachers who consciously act to strengthen their network, display what is recently coined as 'network intentionality' (Moolenaar et al., 2014), that is, agency in forming, maintaining, activating, and dissolving relations to gain access to resources for the mutual benefit of oneself and others, given their own cognitions of what makes for a 'good' network (Nardi, Whittaker, \& Schwarz, 2002). Outside education, scholars have provided evidence that professionals who learned the properties of an effective network, achieved greater performance and career advancement (Burt \& Ronchi, 2007). As such, increasing university teachers' network awareness and intentionality may be a valuable element in a PD program for these teachers. This study designed an intervention to strengthen university teachers' networks in support of their professional development as teachers.

\subsection{Network features related to professional performance}

The literature on performance and expertise development of professionals provides insight into high leverage network features (Cross \& Thomas, 2008; Lin, Cook, \& Burt, 2001). These network features can relate to the composition (the different actors in the network and their attributes) or content of the network (what actually flows through relationships).

Network composition can be explored by measuring the size (e.g., number of relationships that are new, lost or kept) and diversity of networks (e.g., in experience and expertise). Earlier research outside education has suggested that these personal network features are related to professional performance. For instance, high performers engaged in professional interactions with a relatively large number of people (Van Waes et al., 2015a; Parker, Halgin, \& Borgatti, 2016). This does not mean that networks have to be large per se (Roxå \& Mårtensson, 2009). In this regard, two tracks 
can be discerned in network research: the cohesion approach (the bigger the better) and the structural equivalence approach (not all ties are equal). In this paper we consider both tracks, since research shows that high professionals did not only/necessarily develop large networks, but also engaged in behaviors that led to diverse networks (Kilduff \& Krackhardt, 1994; Mehra, Kilduff, \& Brass, 2001). Moreover, large networks have shown to increase the chance of comprising diverse people (Baer, Evans, Oldham, \& Boasso, 2015). Specifically, the networks of high performers have a greater tendency to minimize insularity (Cross, Singer, Colella, Thomas, \& Silverstone, 2010). Diversity in the composition of professionals' networks has been found to impact individual innovation (McFadyen \& Cannella, 2004). Networks that span boundaries improve performance in knowledge-intensive work, because they are tapping into diverse expertise when framing problems or acquiring information (Burt, 1992; Cross \& Thomas, 2008). Crafting a network of diverse actors requires intentionality and opportunity, as research suggests that individuals have a tendency to seek similar others with whom to engage (McPherson, Smith-Lovin, \& Cook, 2001). Studies in education identified access to teaching expertise as a key element in the development of networks (Coburn, Choi, \& Mata, 2010; Spillane, Hallett, \& Diamond, 2003). These findings in organizational and educational research were recently confirmed for the context of higher education. The networks of high performing university teachers typically consisted of people with diverse teaching experience and expertise, and were larger in size compared to their lower performing colleagues (Van Waes et al., 2015a).

Studies on network content, or what actually flows through networks (Bellotti, 2014) show that certain interactions or ties might provide access to more relevant resources than others. Network content characterized by deep interaction or high interdependence between teachers is associated with higher performance and adoption of innovation (Van Waes et al., 2016; Coburn \& Russell, 2008). Cross and Sproull (2004) discerned different informational benefits for professionals when consulting others: solutions (answers to specific questions), meta-knowledge (general guidance or referrals), problem reformulation (considering various dimensions), and validation (bolstering self-confidence and thinking). These informational benefits can result in 'actionable knowledge' (Cross \& Sproull, 2004) which can help find answers, show different perspectives, construct meaning, or offer a soundboard when dealing with professional matters. The frequency with which these different types of content are discussed matters. University teachers who frequently discussed their teaching practice displayed higher performance (Van Waes et al., 2015a).

\section{Hypotheses}

This study aims to examine the extent to which teaching networks can be strengthened during a PD program. Specifically, we are interested in whether an intervention during a PD program strengthens the development of (1) the composition and (2) the content of teaching networks. Firstly, we expect that the intervention affects the size and diversity of the networks, in that the intervention group will develop larger networks (hypothesis 1a) and more diverse networks, i.e. in terms of the teaching experience and expertise of the people in the networks, and their affiliation with the PD program and/or the workplace (hypothesis $1 \mathrm{~b}$ ). Secondly, we expect that the intervention affects the development of the content of teaching networks. We hypothesize that teachers in the intervention condition will more frequently consult others for information or advice around their teaching practice, i.e. in terms of seeking solutions, meta-knowledge, problem reformulation, and validation (hypothesis 2 ).

\section{Method}

\subsection{Context}

This study was conducted in a mid-sized, multidisciplinary, public and research-intensive university in Belgium serving 15,000 students and employing 2855 faculty members, of whom 830 combine a teaching and research appointment. Novice university teachers (i.e., appointed as lecturers or assistant lecturers during the last seven years) can participate in a 18-month PD program to enhance their instructional thinking and practice.

\subsection{PD program}

The central aim of the PD program is to gear participants' teaching practice towards the concept of competence-based and student-activating teaching as embraced by university management. The program starts off with a two-day collective start with sessions on the five key topics of the program: developing, teaching, assessing and evaluating a course, and participating in curriculum development. At the end of the collective start, the participants write a personal teaching project plan, aligning their own objectives with the five key topics of the program. Participants develop practice-oriented material during the program, i.e. directly relevant for and implementable in their instructional practice. Participants are grouped together based on similarities in their project plans, which creates four small, interdisciplinary groups of four to five teachers. Each group is assigned a coach who provides individual feedback on the teaching project over the course of the program. At the end of the program, the participants present and defend their teaching project for an assessment committee (consisting of their coach, the chair of education or another senior colleague, and an expert in education). Overall, the program involves a minimum workload of $150 \mathrm{~h}$.

\subsection{Participants}

The PD program limits participation to 25 university teachers to ensure intensive guidance during the process. Participants enrolled on voluntary basis in the PD program during two subsequent editions: the control group followed the program between December 2011-May $2013(N=22)$, and the intervention group between January 2014-June $2015(N=24)$. Respectively six (control condition) and two teachers (intervention condition) left the program after the first data collection wave, due to new job opportunities (e.g., grants) or maternity leave. Of the remaining 38 teachers, a response rate of $100 \%$ was obtained for all measurement moments. Given our interest in how teaching networks develop over time, we only included the data of these teachers for final analysis. Upon enrolment, participants agreed to take part in research activities and consented to have their data reported anonymously. The control condition consisted of 16 participants ( 12 male; $M_{\text {Age }}=40.38$, $\left.S D=8.53 ; M_{\text {TeachingExperience }}=8.13, S D=6.10\right)$, and the intervention condition of 22 participants ( 15 male; $M_{\text {Age }}=35.09, S D=4.01$; $M_{\text {TeachingExperience }}=7.61, S D=3.68$ ). The gender ratio in both groups is comparable to that at the university as a whole. There is a difference in age, yet, previous research shows that age is not a determining factor in network development of university teachers (Van Waes et al., 2015a). Rather it is the teaching experience that matters, which is similar in both groups. All participants combined a teaching and research appointment. In both conditions participants were equally divided along social/human and hard disciplines. 


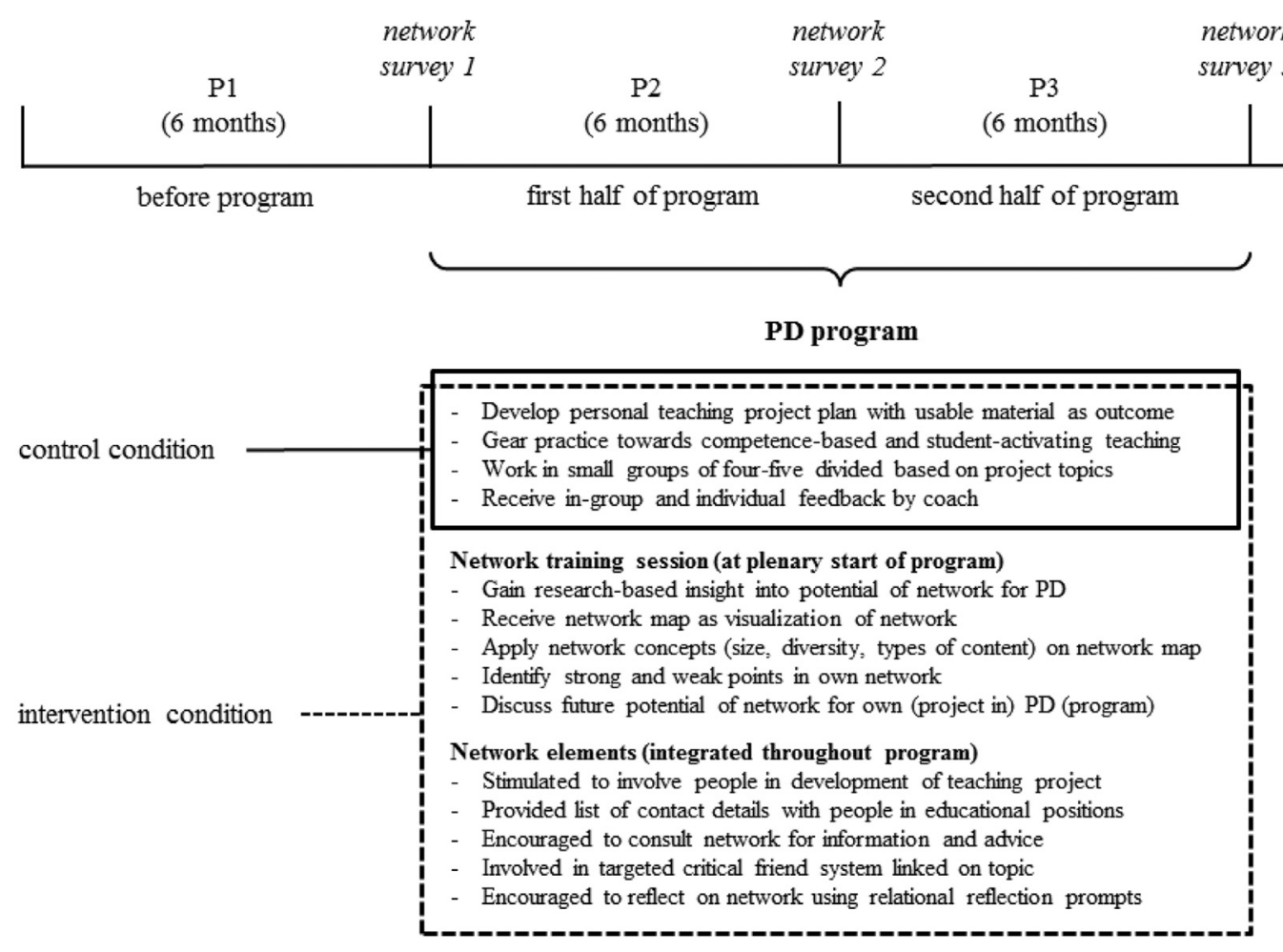

Fig. 1. Overall intervention design.

\subsection{Design}

Fig. 1 displays the longitudinal quasi-experimental design set up to compare the extent to which a control and intervention condition differed in terms of network development before, midway, at the end, and after a PD program. Since participating in the program is voluntary, teachers were randomly distributed over the two conditions. Participants in the control condition followed the PD program as described in 3.2. The intervention condition attended the same PD program, with a network training session at the start and integrated network elements during the program. The intervention design keeps the workload of the intervention group similar to the control group. ${ }^{1}$ The design of the intervention is based on alteration, one of four strategies that capitalize on network data for intervention purposes (Valente, 2012). In contrast to the other strategies, alteration does not assume that networks are static and takes into account network dynamics. An alteration strategy deliberately aims to alter the network to improve efficiency and/or performance. Different tactics of network alteration may be considered, such as (i) adding or deleting alters or ties, and (ii) rewiring existing ties. Adding alters can create new opportunities or resources. Networks can be rewired to increase efficiency or improve performance. By adding, deleting or rewiring alters and/or ties, the network can be maximized on one or several aspects (Valente, 2012). The assumption underlying the intervention design was that individuals, who are aware of their networks and the resources and expertise residing in it, are more likely to reach out to the 'right' people at the 'right' time when presented with challenges or opportunities (Borgatti \& Cross, 2003). As such raising teachers'

\footnotetext{
1 Potential contamination (e.g., a participant from the control group is mentioned in the network from the intervention group) was possible in both conditions since the PD program already ran in this format before the control group edition.
}

network awareness was a key element of the intervention.

At its core, the intervention consisted of a network training session to raise teachers' network awareness (cf. Baker-Doyle, 2011; Cross et al., 2010; Uzzi \& Dunlap, 2005). This session took place at the plenary start of the PD program. In the session, teachers were introduced to the idea of 'teaching networks' (i.e., the people they discuss their instructional practice with, consult for information or advice) and how these may help them to improve their practice. Before the plenary start, participants had filled out a network survey to map their networks (3.6). Based on these surveys, a personal network map was generated for each participant on A3-sized paper (Fig. 2) to visualize their teaching network (Hogan, Carrasco, \& Wellman, 2007). These network maps served as a tool during the training session to introduce and apply several network concepts, related to network composition (e.g., How diverse is my network in terms of teaching experience? Does my network consist of ties to people both within and outside the department/university?), and network content (e.g., which ties do you consult for solutions or problem reformulation?). Participants identified strong and weak points in their networks (network gap analysis technique, Cross et al., 2010, p 0.198), and examined if and how their network could support and/or hinder them during the PD program and in their practice. Strategies were introduced to rewire and maximize the networks in light of their professional development (Valente, 2012). As a consequence of growing awareness of their networks, participants could complete information about their networks in the surveys. Participants were encouraged to explicitly reconsider their networks each time they updated the network survey. The training session took up $45 \mathrm{~min}$, and was first piloted in a small group.

Furthermore, over the course of the program several network elements were integrated. These were aimed at sustaining the transfer of the training session. Specifically, these network elements continually refresh the strategies of adding/deleting and 


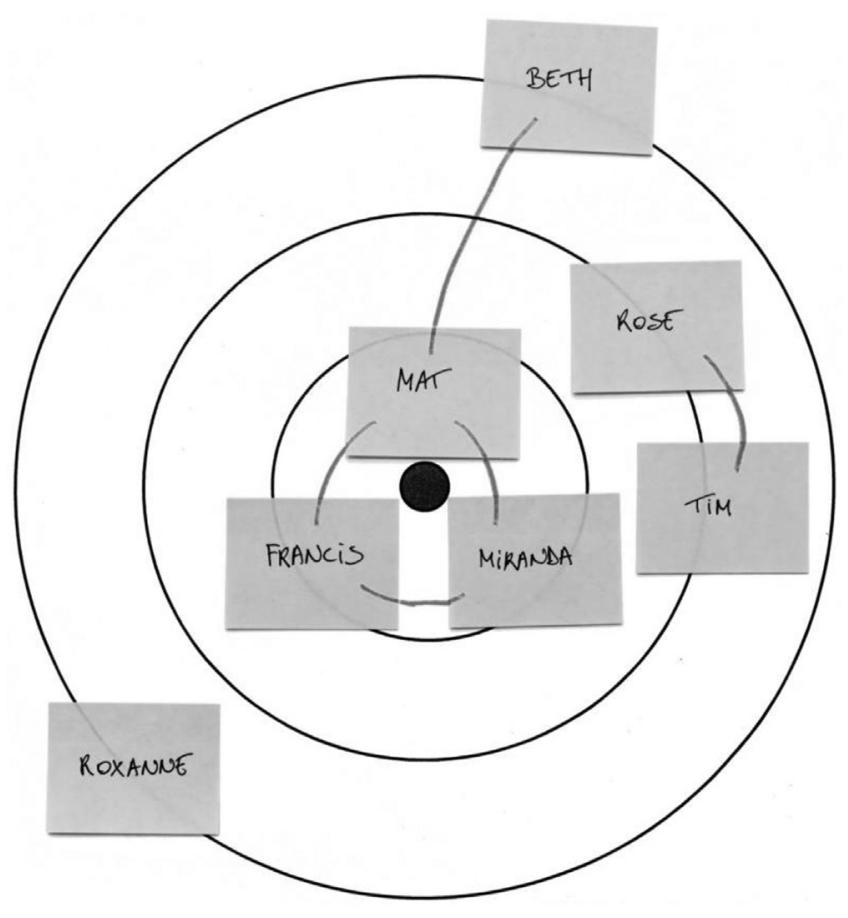

Fig. 2. Example of a network map (based on network survey 1) provided at the network training session in the intervention condition.

rewiring alters and ties to maximize the networks' potential. When writing up their project plans, participants were encouraged to include people that might contribute to the development of their project (e.g., people in educational boards, central services, other participants, colleagues at the department). A list of contacts was added to the learning materials ('know-what') containing contact details of people holding education-related positions ('know-who'). Whenever relevant, the coaches referred to the networks as a potential tool when participants had questions or encountered difficulties, as many questions or issues are context-specific. Moreover, within the small-group meetings a targeted critical friend system was developed, connecting participants based on their project topics. Finally, critical reflection guidelines contained relational prompts (e.g., Who could further advance your practice regarding this objective?).

\subsection{Procedure}

In both conditions, network data were gathered over a two year time-frame. An identical network survey was administered by internal mail four times at fixed time intervals aligned with the program, each spanning a period (P) of six months. The first network survey was administered before the start of the program (P1), the second survey was filled out midway the program when participants submitted a formative version of their teaching project (P2), the third survey took place at the end of the program right after the final submission of the project (P3), and the last survey was distributed half a year after completion of the program (P4). In the intervention condition, the network training session took place after P1, during the plenary start of the program. The other network elements were embedded during the program (P2-P3).

\subsection{Data collection}

We took an ego-network approach to social network analysis
(Crossley et al., 2015), meaning that networks were mapped centered on an individual (ego). The people that an individual interacts with are alters, and the relationship between ego and alter is a tie. The benefit of using this approach is that participants can map their networks from the ground up. It allows participants to define their own network boundaries, which opened up the opportunity to capture relationships beyond the boundaries of the department or university. This was an important consideration, given our focus on professional development, to include external professional contacts as well.

A network survey (Borgatti, Everett, \& Johnson, 2013) was used to capture each participant's teaching network. The central open-ended question was: 'Write down the names of the people you communicate with about your instructional practice. This includes talks/calls/e-mails about preparing and teaching courses, teaching methods, student guidance, student assessment, thesis students and student evaluations.' We specified that we were not looking for administrative or legal discussions about education. Each time the survey was administered, a clear time frame was set (six months) to gain insight into their current networks. People from within or outside the university could be included. We also indicated that network size could be small or large depending on the participant's specific situation. Follow-up questions further inquired about the attributes of alters and ties, to obtain information on the composition and content of participants' networks. From network survey 2 onwards, an overview of the alters listed in the previous survey was provided for every participant individually. This overview served as a reminder to prevent measurement error (e.g., 'new' or 'lost' ties due to forgetfulness or potential name confusion). It allowed participants to update their networks by first indicating which connections were lost over time, with whom they still interacted, and which relationships were new.

\subsection{Variables}

Network composition. At each measurement occasion the size of participants' networks was calculated by counting the ties in the different networks. By comparing network size matrices between the measurement occasions, the number of new, lost and kept ties was calculated. Diversity in network composition was measured by mapping the diversity of various alter characteristics within the personal teaching networks. In specific, diversity in alters' teaching experience and expertise was measured, as well as alters' diversity in affiliation to the same or a different department, and their involvement in the PD program. The teaching experience of participants' alters was measured on a scale varying from 1 (none) to 6 (more than 30 years). This variable was recoded into a dummy variable, indicating whether the ego connected to alters with similar teaching experience (1) or different teaching experience (0). To gain insight into the teaching experience of participants' alters at different measurement occasions, rating scales of all alters within a network at every occasion were totaled. Alters' teaching expertise ('This person has teaching expertise regarding instructional matters') was measured on a scale varying from 1 (do not agree) to 7 (totally agree). Similarly, rating scales of all alters within a network at every occasion were totaled. Participants indicated whether alters belonged to the same or a different department. Whether alters were involved in the PD program was tallied on name-basis.

Network content. Four questions were posed to gain insight into the content of participants' teaching networks. These questions concerned different kinds of relational network benefits (Cross \& Sproull, 2004), i.e. solutions ('how often have you turned to this person ... for specific or detailed questions about your instructional 
practice?'), meta-knowledge (' ... for information about other sources of information or people concerning your instructional practice?'), problem reformulation (' ... to help you think about questions or problems related to your instructional practice?'), and validation (' ... to simply talk and bolster your thinking and selfconfidence about your instructional practice'). Finally, in relationship to the PD program, we asked the participants for each alter how often they had discussed their teaching project. These questions were measured on a frequency scale varying from 1 (never) to 7 (daily).

To approximate a normal distribution (J. Fox, 1997) a logittransformation was applied on all continuous dependent variables.

\subsection{Data analysis}

To obtain an overview of the differences in network development between the control and intervention condition, we drew on multilevel models, using MLwiN (Rasbash, Steele, Browne, \& Goldstein, 2016). Multilevel models explicitly take into account the nested data and related dependency structure of personal networks (Crossley et al., 2015; Wellman \& Frank, 2001). Multilevel techniques also give more specific insight how personal networks change: "They allow to distinguish between the influence of individual and of tie characteristics on the stability of personal networks as a whole and of specific ties within a personal network" (van Duijn, van Busschbach, \& Snijders, 1999, p. 187). The data of this study has a complex structure as it contains information on various ties (teaching relationships) pertaining to ego's (participants). These ties comprise multiple observations (maximum four) over time. Data on a total of 1670 ties was analyzed for 38 ego's (control condition $N=389$, intervention condition $N=1281$ ).

For the network attributes related to network composition (size and diversity), the development was studied at ego-network level. A model of analysis was used to estimate average values for each combination of Group x Measurement Occasion (e.g., average network size for the intervention group at P2). These eight parameters (2 Groups x 4 Measurement Occasions) constituted the fixed part of the model. In a next step, variance between participants (or ego's) regarding these eight averages was allowed. This defined the random part of the model, i.e., describing differences between participants within the control or intervention group. This random part of the model allowed us to measure the diversity in the personal teaching networks.

For the network attributes related to network content (e.g., the frequency of seeking solutions for each tie in a network), two different models were estimated, i.e. at ego and at tie level. These models show a more complex picture since we were not only interested in how participants used the network as a whole and how this developed (ego-network level), but also in how each separate tie is used and how this developed (tie level). The analyses at tie level provide information about how purposively participants used their network (e.g., do they use all their ties equally for problem reformulation or do they consult a specific set?) This can be deduced from the extent to which ties within ego's differ on a certain measurement occasion. The observations are nested within ties and within ego's. For these network attributes, average values were estimated likewise for each combination of Group x Measurement Occasion (fixed part). Finally, variances between alters were estimated (random part). In addition, to the tie level models, ego level models were estimated. Tie level models do not take into account the size of participants' networks, and thus disregard the fact that participants with a larger network have teaching ties with more people. From a network perspective it is relevant to know whether participants consult one person for problem reformulation purposes, or gain perspectives from four different persons within their network. This last approach is intrinsically related to network size (i.e. number of ties). Sum scores were calculated to obtain information about these variables at ego-network level.

For all models $\chi^{2}$ tests were used to test whether differences were significant between averages at different occasions for both groups, between differences in development of averages for both groups, and between variances at different occasions for both groups (see Appendix).

\section{Results}

\subsection{Network composition}

\subsubsection{Network size (H1a)}

The fixed part of the model shows that both groups increased in network size after the start of the PD program (Table 1 in the Appendix). Yet, despite existing differences between both groups in network size before the start of the PD program (P1), the intervention group showed a steeper increase in average network size at the start of the PD program (from P1 to P2), adding on average 6.78 people to their networks, compared to the control group who added 2.38 new ties $\left(\chi^{2}(1)=4.53, p<0.05\right)$ (Fig. 3). This increase took place at the start of the PD program, after the network training session. The random part shows less variation for the intervention group $\left(\chi^{2}(1)=5.12, p<0.05\right)$, indicating that the increase between $\mathrm{P} 1$ and $\mathrm{P} 2$ happened for most participants in this group. In contrast, some participants in the control group enlarged their networks and others did not, suggesting that the PD program influenced the network development of some participants but not all. In both groups, the overall increase in network size remained constant after completion of the PD program, meaning that participants' networks grew during the PD program and remained larger in overall size up until six months after the program had finished.

Figs. 4 and 5 show that participants in the intervention group did not simply add more ties to their teaching networks, they also lost more ties in the second half of the PD program (P2-P3) $\left(\chi^{2}(1)=5.18, p<0.05\right)$, indicating an increased level of network dynamics over the course of the program in comparison with the control group.

\subsubsection{Network diversity (H1b)}

At the end of the PD program (P3), the intervention group indicated that on average they had 3.43 ties to people involved in the program (i.e., other participants, coaches), compared to 1.88 ties in the control group $\left(\chi^{2}(1)=4.29, p<0.05\right.$ ) (see also Table 2 in the Appendix). The network between participants within the intervention group also grew more dense, meaning that the participants within the intervention group discussed their teaching practice more with each other than the control group $\left(\chi_{\mathrm{P} 2}^{2}(1)=10.29\right.$, $\left.p<0.01 ; \chi_{\mathrm{P} 3}^{2}(1)=5.52, p<0.05 ; \chi_{\mathrm{P} 4}^{2}(1)=4.86, p<0.05\right)$. In both groups, ties to people involved in the PD program were maintained even after completion of the program (P4). Moreover, participants in the intervention group did not only add ties related to the PD program, they also enlarged their local network at the department. After the start of the PD program (P1-P2), the network at the department of the intervention group grew substantially compared to the control group $\left(\chi^{2}(1)=8.57, p<0.01\right)$ (Figs. 6 and 7 ).

Regarding the teaching experience of the alters within the networks, we noted that the control group increasingly connected to people with similar teaching experience towards the second part of the PD program (P2-P3), compared to the intervention group $\left(\chi^{2}(1)=3.94, p<0.05\right)$. Furthermore, the total teaching expertise of the people within participants' networks increased in both groups after the start of PD program. Yet, the intervention group showed a 

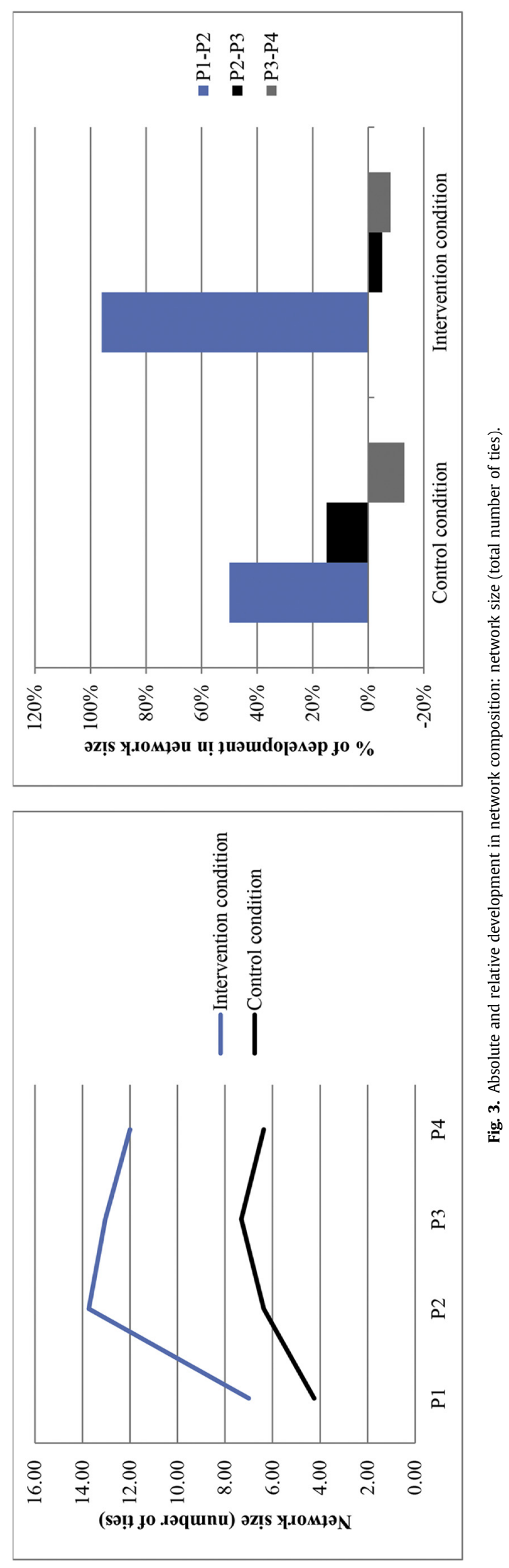

steeper increase as they doubled the total teaching expertise within their networks $\left(\chi^{2}(1)=16.68, p<0.001\right)$. In sum, these findings suggest that the intervention affected the development of network size (H1a) and diversity (H1b).

\subsection{Network content (H2)}

Concerning the content of participants' teaching networks (i.e. the interactions around their teaching practice regarding seeking solutions, meta-knowledge, problem reformulation and validation, and the frequency of these types of interactions) two approaches were taken. This resulted in information about how they used the network as a whole during the PD program (egonetwork level), and about how each separate tie is used during the program (tie level). The ego-network level results overall demonstrate that when participants in the intervention group enlarged their networks (4.1.1), they did not reduce the frequency of contact with their teaching ties (see Table 3 in the Appendix). So they increased their network and at the same time kept up the frequency of interaction around their teaching practice regarding seeking solutions, meta-knowledge, problem reformulation and validation. This development in network content showed clearly in the first half of the PD program (P1-P2), and differed from the control group $\left(\chi^{2}\right.$ Solutions $(1)=13.34, p<0.001 ; \chi^{2}{ }_{\text {Meta- }}$ knowledge $(1)=12.76, p<0.001 ; \chi^{2}$ ProblemReformulation $(1)=10.88$, $p<0.01 ; \chi^{2}$ validations $\left.(1)=7.52, p<0.05\right)$. Moreover, this increase in total frequency of interaction around the teaching practice was maintained until after completion of the PD program (P4).

The tie level results showed few differences in content between the control and intervention group, indicating that both groups used their ties in similar ways to seek information or discuss their teaching practice during the program (see Table 4 in the Appendix). The one difference between both groups was that the intervention group showed higher variance between ties when seeking others to talk through teaching related problems (problem reformulation). This was the case from the start of the PD program onwards, and even grew stronger after the program had finished $\left(\chi_{\mathrm{P} 2}^{2}(1)=7.02\right.$, $\left.p<0.05 ; \chi_{\mathrm{P} 3}^{2}(1)=6.74, p<0.05 ; \chi_{\mathrm{P} 4}^{2}(1)=11.46, p<0.01\right)$. This means that participants in the intervention group started to differentiate in which ties they used for problem reformulation, whereas the control group used each tie about equally.

Finally, as the program evolved, participants in the intervention group showed a slight tendency to discuss the PD program and their teaching project more often, compared to the control group $\left(\chi^{2}(1)=3.40, p=0.065\right)$ (also see Table 4 in the Appendix). The intervention group also showed higher variance in the random part of the model, indicating that participants discussed their teaching project with some people in their network and not with others, whereas this was more uniform in the control group $\left(\chi_{\mathrm{P} 2}^{2}(1)=3.83, p=0.05, \chi_{\mathrm{P} 3}^{2}(1)=12.06, p<0.01, \chi_{\mathrm{P} 4}^{2}(1)=6.71\right.$, $p<0.05)$. In sum, these findings show that the intervention affected network content at ego-level, and thereby partly confirm hypothesis 2.

\section{Discussion}

This study examined the extent to which personal network features relevant to professional development can be strengthened during a PD program in higher education. Thus far, studies have examined teachers' interactions during PD programs in a mainly descriptive and cross-sectional way. This work provides empirical evidence on an intervention conducted to strengthen teachers' network development. Moreover, a novelty of this study was that it provided a longitudinal account (over a two-year time frame) of how networks may change during a PD program, also considering 


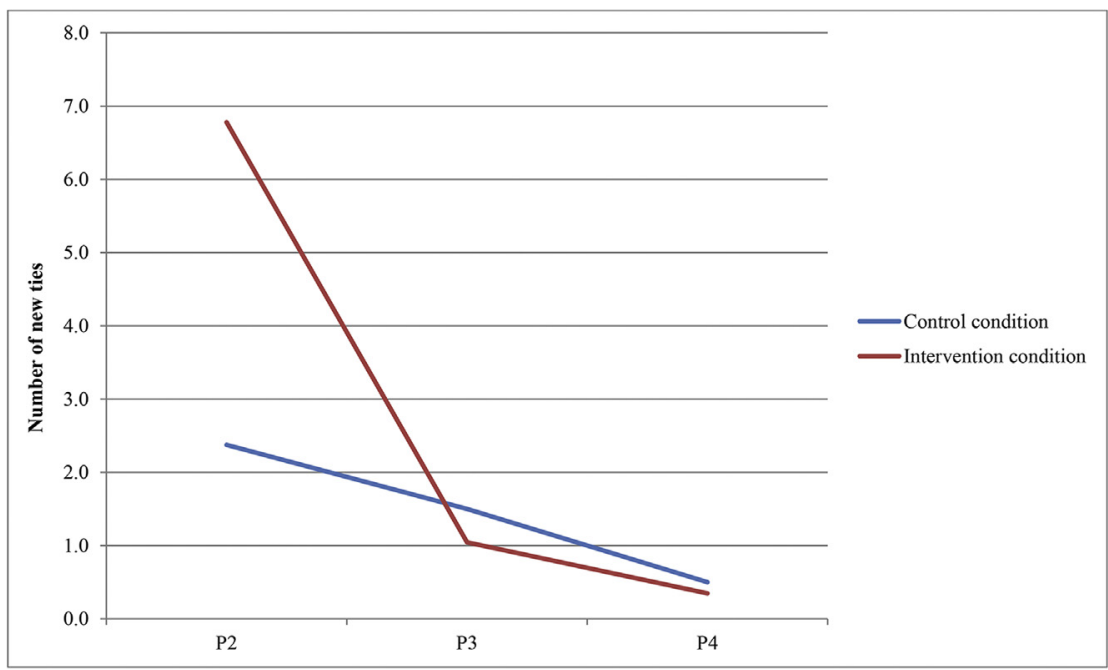

Fig. 4. The development in network composition: number of new ties.

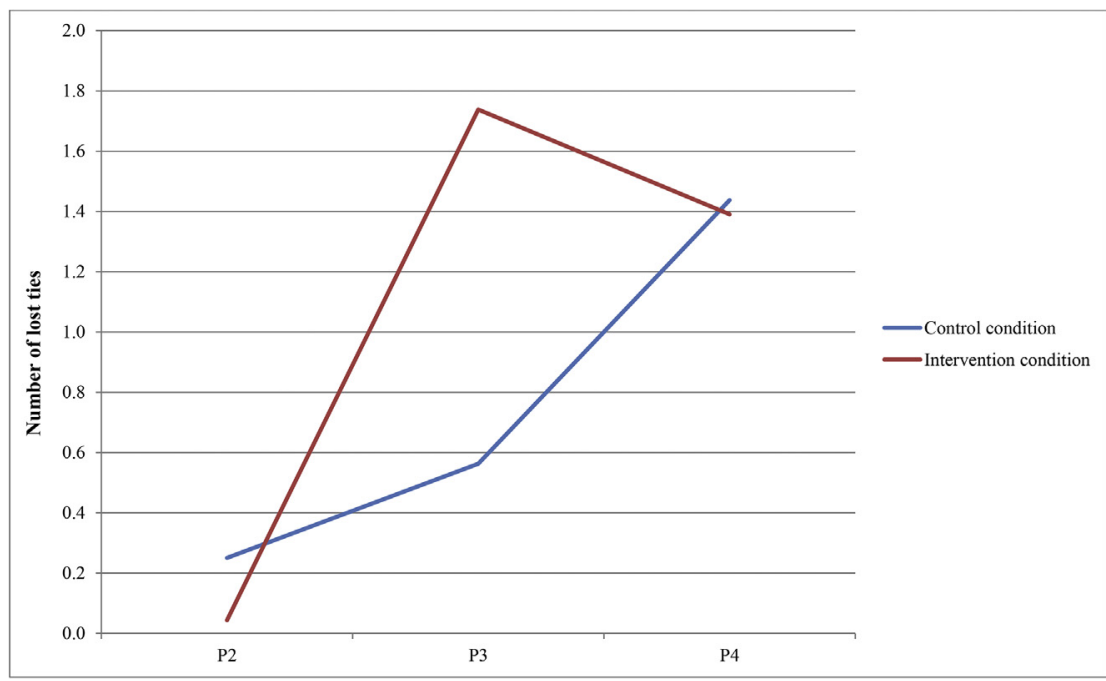

Fig. 5. The development in network composition: number of lost ties.

the period after completion of the program. Overall, our study showed that teaching networks can be strengthened during a PD program, as evidenced by differences between the control and intervention condition in network composition and content. We discuss three key themes that emerged from this study and may yield suggestions for practice and research.

\subsection{The intervention group increased network size and network dynamics (H1a)}

The inclusion of multiple measurement periods allowed insight into how the size of the teaching networks evolved at specific periods before, during and after the program. In line with previous research (e.g., Rienties \& Kinchin, 2014), findings showed that networks in both the control and intervention group increased in size during the PD program. Despite existing differences between both groups in network size before the start of the program, the intervention group showed a steeper increase in average network size; indicating an effect of the intervention. The focus of our study is on the development of networks. Yet, it could be true that teachers with a larger starting network have a higher chance of showing further network development after intervention. In both groups, the increase in size of the teaching networks was maintained until at least six months after completion of the program. This suggests that for this time period, the program had a sustained influence on participants' teaching network.

Furthermore, teachers in the intervention condition did not only develop larger teaching networks, their networks were also characterized by increased dynamics. Specifically, teachers in the intervention condition did not only form more ties, they also dissolved more ties, yet overall maintaining larger networks than the control condition. The latter implies a sustainability effect of the intervention. The increase in network dynamics may also imply that the intervention group explored their networks at the start of the PD program in light of increased network awareness. As the program proceeds, they narrowed down the network again, possibly to reflect their needs in development at that time. As our findings demonstrated that the networks changed most 


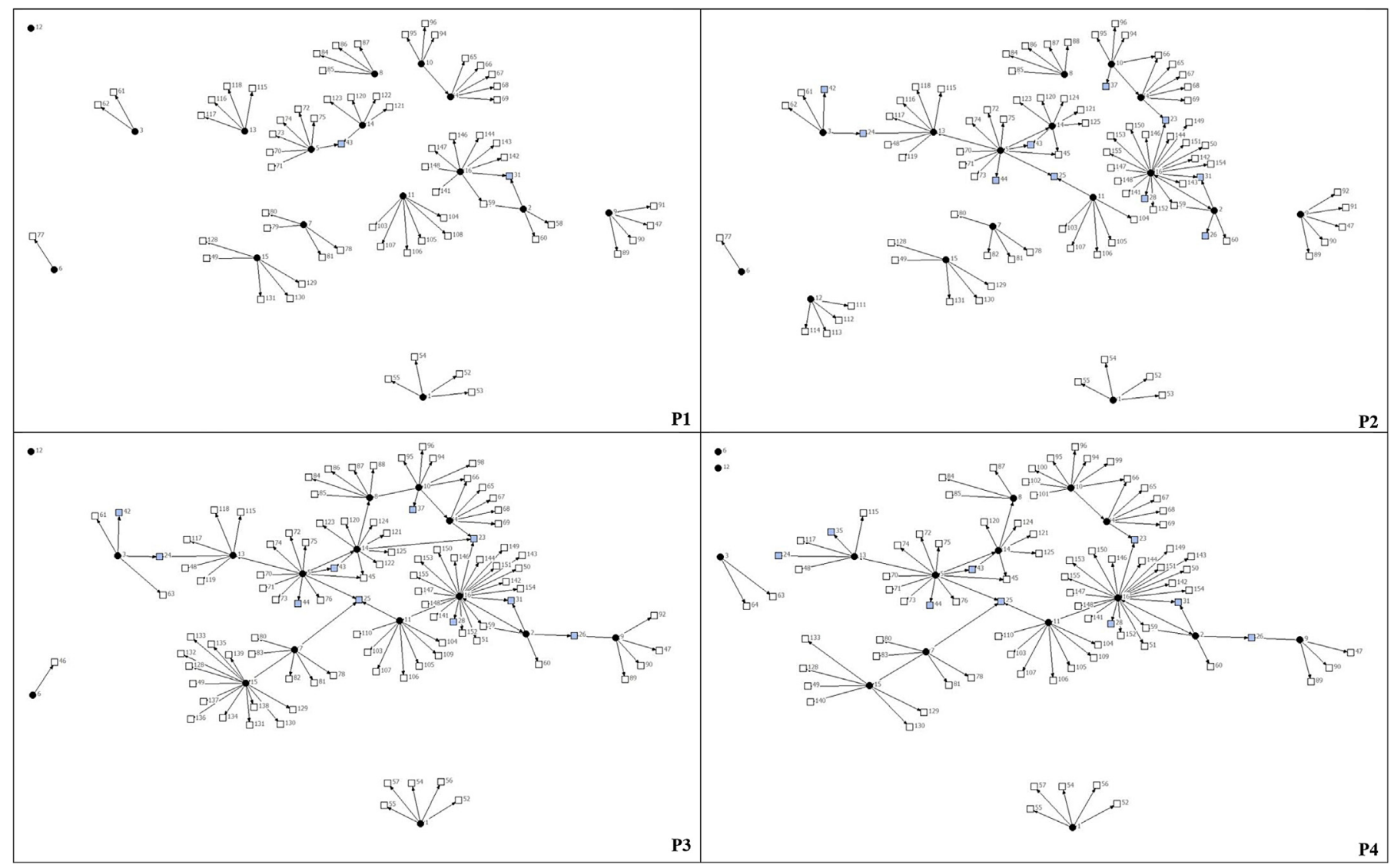

Fig. 6. Results of the development in network composition in the control condition.

significantly between the start and midway point of the program, a suitable moment for network interventions may be at the beginning of a program. Our study also showed that teaching networks can be affected significantly through short interventions, and may be sustained by implementing other network elements during the program.

Underlying the network intervention in this study, was the assumption that change in network behavior is caused by raising teachers' awareness of their personal teaching networks. When teachers become aware of their network, they can act intentionally by using and maintaining existing ties, forming new ties, or dissolving ties (Moolenaar et al., 2014). Future intervention studies should further grasp the extent to which teachers acted more intentionally on their networks, and/or grew increased awareness about their networks. Future (qualitative) work could also grasp the processes underlying tie formation, maintenance and dissolution (Spillane \& Shirrell, 2017) to further understand the different meanings and reasons for network development.

There are several possible arguments in favor and against generalizability of our intervention findings. For example, the typical professional activity of university teachers might be mainly individual work, whereas in other professions collaborative and cooperative activities are paramount. It may be expected that the importance of network relations is quite different in such professions. University teachers represent a specific subset of teachers, who combine different job responsibilities such as research, teaching and social services. The pressure for publication is high, and the juggling of responsibilities has undoubtedly an impact on the time and effort faculty members can and want to invest in their teaching practice. Faculty members are mostly evaluated on their individual merits and less as a team or department, which may impact the patterns and constellations of their teaching networks. Even though one cannot adopt our work indiscriminately to other contexts, the design principles and findings of the network intervention can be generalized to similar teaching qualification programs. To advance the design of network interventions in light of professional development, future studies should compare and contrast interventions at different times and in different settings and institutions. Future research should also provide further empirical evidence on which (combination of) network elements offer(s) what kind of contribution, and should explore other elements (e.g., self-selected peer coaches, observation of (senior) colleagues' teaching).

\subsection{The intervention group developed more diverse networks ( $H 1 b)$}

The intervention group showed an increase in diversity as their networks consisted of people from within the PD program (coparticipants, coaches) as well as outside the PD program (colleagues at the department, people in educational central services). The control group showed less diversity in network composition. When enlarging their networks during the PD program, they increasingly connected to people with similar teaching experience. Network diversity is linked to opportunities for innovation (Kilduff \& Krackhardt, 1994) as one can tap into diverse sources of teaching expertise and experience when framing problems acquiring 


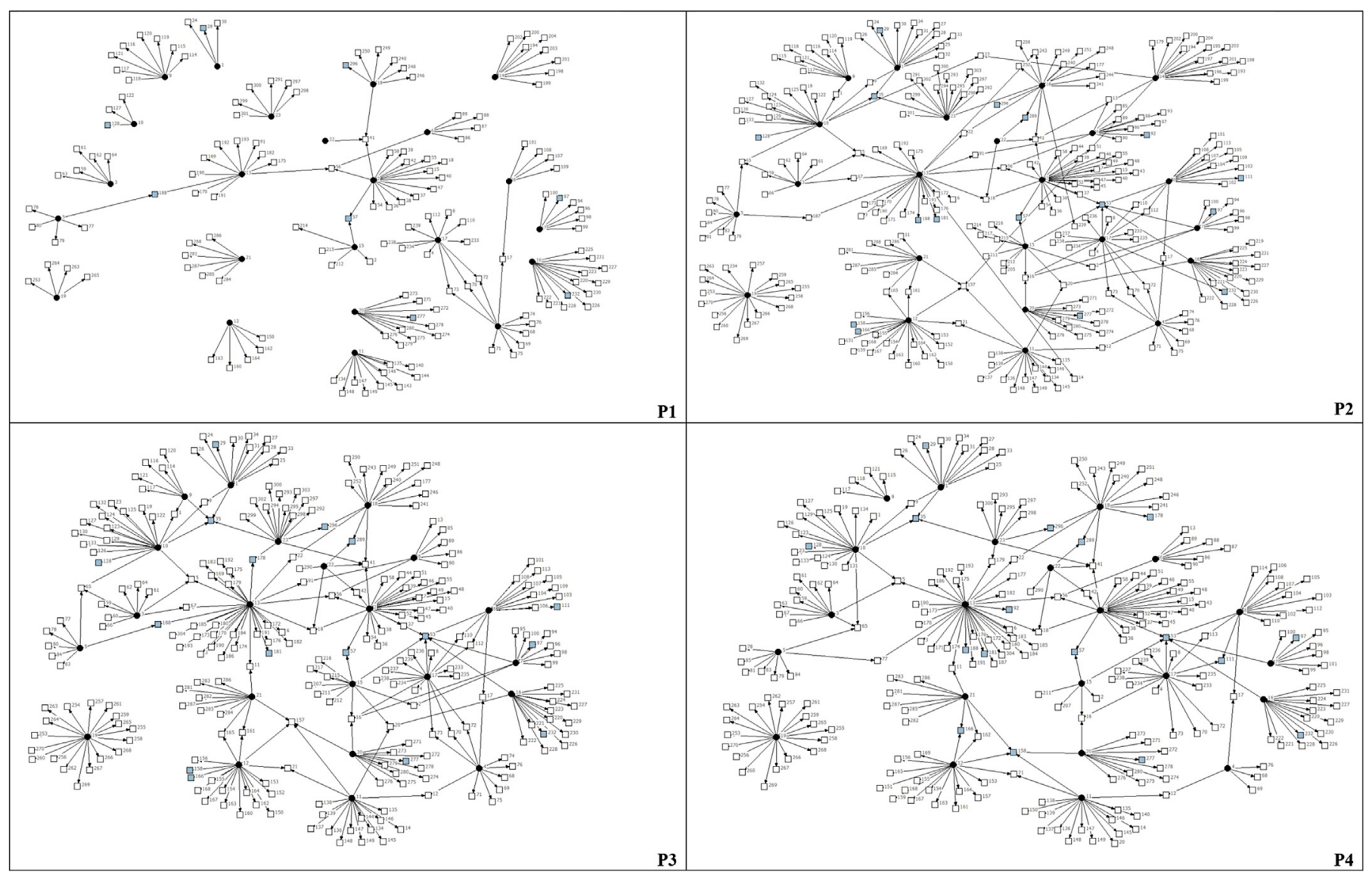

Fig. 7. Results of the development in network composition in the intervention condition.

information to solve them (Van Waes et al., 2015a; Burt, 1992; Cross \& Thomas, 2008). Furthermore, the control group showed limited interaction between participants within the PD program, and less conversations about teaching with colleagues at the department compared to the intervention group.

Overall, we note that in both groups the networks between participants remained sparse. The intervention teachers developed more ties with other participants, but still this concerned few ties. Large distances between several participants remained in both groups, implying that teaching resources did not spread easily among the program participants. It is remarkable that participants indicated few relations with co-participants, since they provided feedback to each other as part of a critical friend system and worked in small groups. A possible explanation may be that the teaching project in this PD program was an individual endeavor aimed at their teaching practice at the workplace. Perhaps, if the program would have included collective tasks or shared goals, connections between participants may have grown stronger (Rienties \& Kinchin, 2014).

The intervention group especially developed ties to people outside the PD program at their workplace. Scholars have argued that participants' workplace connections are a significant factor in facilitating transfer of training (Hatala \& Fleming, 2007; Van den Bossche \& Segers, 2013). If what is learned during the PD program is not supported or is contradictory to what happens at the workplace, transfer will be less likely, and teachers are likely to fall back on older practices (Blume, Ford, Baldwin, \& Huang, 2010). A network approach to PD programs seeks to reduce how training is often separated from practice at the workplace, as has previously been raised by scholars (Tynjälä, 2008). We believe these are important implications for practice. Academic developers may explicitly consider strengthened networks as an outcome of PD programs as network development could augment and sustain the effects of PD programs (Penuel et al., 2012; Thomson, 2015). Yet, the balance between fostering network awareness and imposing network building is a delicate and critical one (Brown \& Duguid, 1991; Datnow, 2011).

\subsection{The intervention group consulted a wider network of people for different types of content ( $\mathrm{H} 2$ )}

A novelty of this study was that it also considered different types of content that are exchanged, whereas most studies only focus on the composition of networks. Findings demonstrated that participants in the intervention condition increased the total time they spent consulting their teaching network for information and advice. This suggests that participants discussed their teaching practice with more people to seek solutions, meta-knowledge, problem reformulation and validation. Having a wider network has been shown to increase the likelihood of encountering actionable knowledge (Cross \& Sproull, 2004). The network intervention also stimulated participants in the intervention group to discuss their teaching project and the PD program more frequently compared to the control group.

Scholars should further explore the depth and interdependence of teachers' interactions, using qualitative (network) techniques (Bellotti, 2014), as these have proven consequential in studies on professional development (Van Waes et al., 2016; Coburn \& Russell, 
2008). Qualitative research could also enrich insight into how 'negative or difficult ties' (Everett \& Borgatti, 2014) may constrain or hinder teachers when following PD programs as these may influence the transfer to the workplace. Overall, these findings further nuance the adage of 'the bigger the network, the better'. This study raises further questions about how network size interacts with the content and diversity of the network (do larger networks offer more opportunities for diverse input and/or complementary content?), and which (combinations) matter for professional development. Depending on what teachers need in light of their professional development, some may show increased network dynamics or diversity, but not necessarily larger networks. This touches upon the two approaches of cohesion (the bigger the better) and structural equivalence (not all ties are equal) in network research. This study addressed both approaches. Future work should examine if we should both strengthen cohesion and structural equivalence in network interventions to foster professional development. A further deepening of the structural equivalence approach, beyond network content, can bring more understanding (e.g., by tracing learning cultures, or the value created through networks).

\section{Delimiters}

Our work is also bounded by a few delimiters. In this study, we have taken a quantitative approach to assess the strengthening of networks. However, it would be valuable to examine not only the increase in (diversity of) ties and its content, but also to gain more insight in qualitative nature of these ties. For instance, future work may explore whether network-oriented PD programs may also contribute to more in-depth, targeted discussions around teaching. In addition, future work should provide further insight into the complex interplay between the development of networks and outcomes such as teaching performance and student results. For example, do teachers with higher network diversity also show improved teaching skills? Potential outcomes could be assessed using student evaluations, student achievement results, (peer) observations of teaching, peer nominations, and think aloud interviews on teaching approaches and behavior. A next step is to analyze how variations in interventions amplify or erode performance effects. Yet, investigating the relation between network and performance outcomes is very delicate work as change in teaching practices takes time and is hard to track (Stes et al., 2007; Stewart, 2014). Therefore, we would argue that further research may benefit from longitudinal mixed methods approaches to explore these types of questions.

Next, our work focused on strengthening network development, and started from the knowledge base on high leverage network features related to performance and expertise development. It did not (further) examine the relation between network and performance outcomes to investigate (causal) relationships. Future work should provide further insight into the complex interplay between how networks and performance develop. Do certain network features support professional development? Or do developments of individual attributes come along with developments of the networks?

Furthermore, this study used an ego-network approach by mapping the networks of individual teachers and allowing them to set the boundaries of their network, without assuming pre-existing boundaries. A limitation of such an approach is that it negates an overall 'systems' perspective that is gained by taking a whole- network approach (e.g., by including the ties of all teachers within an academic department). However, not properly attending to the individual in favor of the whole network results in an incomplete picture as well (Kilduff \& Krackhardt, 1994). As such, it may be valuable for future work to capture both teachers' ego- and whole networks during a networked intervention.

Finally, information about network change as reported in this study, was based on self-report measures. Research provides evidence that an individual's perception of his/her network proves more consequential than the actual structure of the network (Kilduff \& Krackhardt, 1994). Yet, an area ripe for exploration in network research is to triangulate self-reported network data with other data sources, such as tracking interactions through logs, emails or documents, socio-metric badges, observation, or interviewing/surveying the alters in the network as a member check (snowball method).

\section{Conclusion}

This work further demonstrates the value of networks for teachers' professional development. In higher education, the reduction of isolated practice to improve teaching quality is high on the policy and research agenda. This study shows that the development of university teaching networks can be strengthened through intervention, not only affecting the network composition in size and diversity but also influencing the content of what is exchanged around the teaching practice. Moreover, as demonstrated, networks can be strengthened over a short time period. This study yields several suggestions for practice and research on network interventions to strengthen professional development. It highlights the potential of enhanced social networks as an outcome of PD initiatives, supplementary to the existing focus on individual outcomes.

\section{Appendix}

\section{Results of multilevel analyses for network composition and content}

Note: For sake of transparency, we included the tables of the multilevel analyses. The main results are incorporated and illustrated in the manuscript itself.

\section{Legend}

Fixed part: This part of the model gives an overview of the extent to which the control and intervention group differed on average at each MM.

Random part - ego and alter: This part of the model shows the random residuals that were estimated for the ego and alter/tie levels, yielding a variance parameter between egos (i.e., describing differences between participants in the control and intervention condition) and within egos (i.e., describing differences between relations within participants' networks) at every MM.

Exp: The exponent is the inverse of LN, the natural logarithm.

a For this variable, variance is estimated at 0.00 at P2. Participants in both the control and intervention group lost near to none ties. Therefore, comparison of differences was not useful.

b For this variable, variance is estimated at 0.00 at P1. Participants in both the control and intervention group had near to none ties to other participants before the PD program (P1). Therefore, comparison of differences was not useful. 
Table 1

Results of the multilevel analyses for network composition: network size.

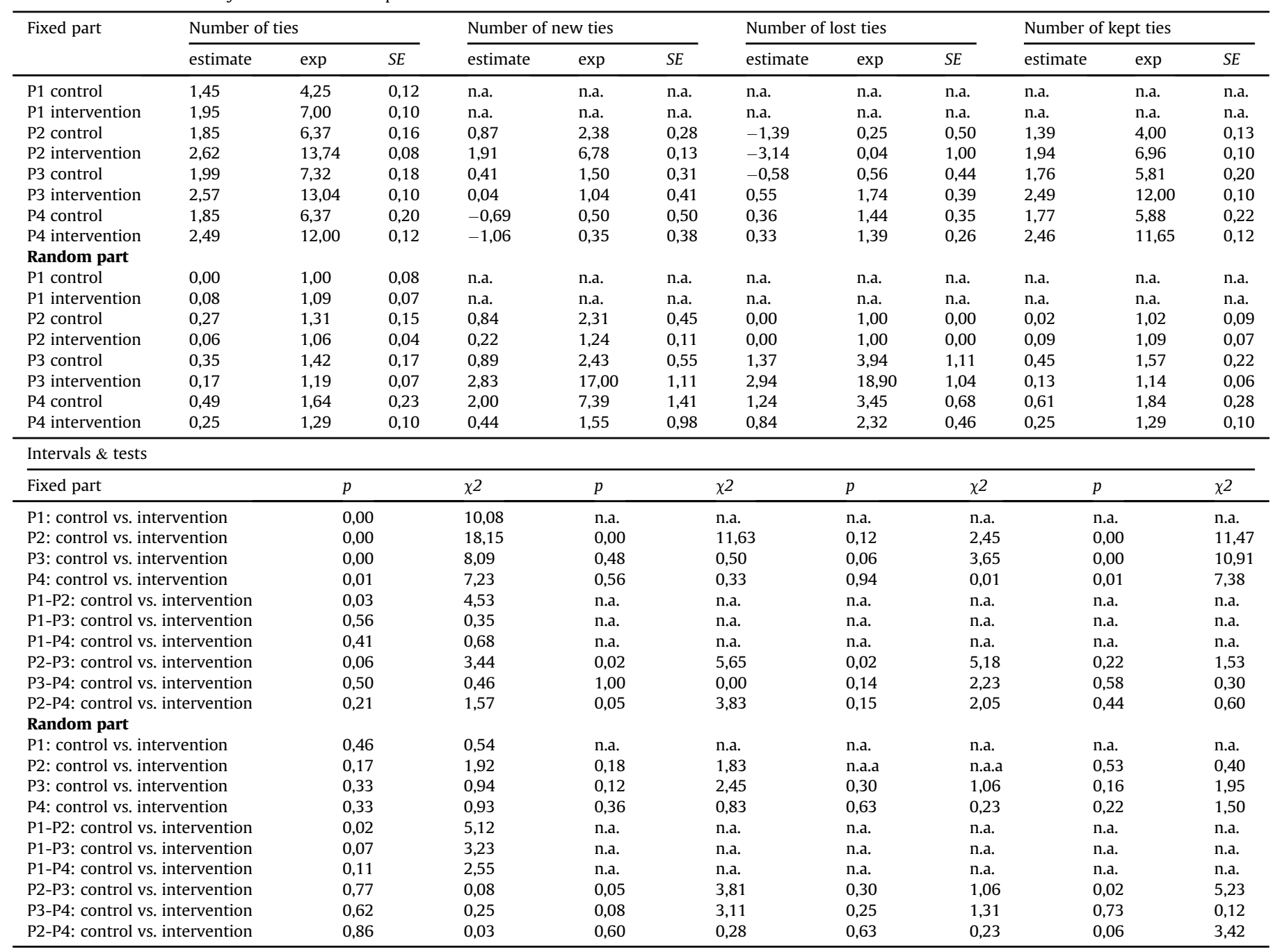

Table 2

Results of the multilevel analyses for network composition: network diversity.

\begin{tabular}{|c|c|c|c|c|c|c|c|c|c|c|c|c|c|c|}
\hline \multirow[t]{2}{*}{ Fixed part } & \multicolumn{2}{|c|}{ Teaching expertise } & \multicolumn{3}{|c|}{ Teaching experience } & \multicolumn{3}{|c|}{ Ties within PD program } & \multicolumn{3}{|c|}{ Ties to participants } & \multicolumn{3}{|c|}{ Ties to department } \\
\hline & estimate & $S E$ & estimate & $\exp$ & $S E$ & estimate & $\exp$ & $S E$ & estimate & $\exp$ & $S E$ & estimate & $\exp$ & $S E$ \\
\hline P1 control & 24,56 & 3,44 & 0,00 & 1,00 & 0,31 & $-0,58$ & 0,56 & 0,33 & $-2,77$ & 0,06 & 1,00 & 1,01 & 2,75 & 0,17 \\
\hline P1 intervention & 36,30 & 4,40 & 0,69 & 2,00 & 0,15 & $-0,04$ & 0,96 & 0,21 & $-1,34$ & 0,26 & 0,42 & 0,96 & 2,61 & 0,15 \\
\hline P2 control & 36,88 & 6,61 & 0,36 & 1,44 & 0,23 & 0,63 & 1,88 & 0,27 & $-0,83$ & 0,44 & 0,40 & 1,22 & 3,37 & 0,22 \\
\hline P2 intervention & 72,74 & 6,12 & 1,42 & 4,13 & 0,12 & 1,23 & 3,43 & 0,12 & 0,58 & 1,78 & 0,17 & 1,57 & 4,78 & 0,13 \\
\hline P3 control & 42,44 & 8,10 & 0,60 & 1,81 & 0,22 & 0,92 & 2,50 & 0,23 & $-0,38$ & 0,69 & 0,36 & 1,29 & 3,63 & 0,21 \\
\hline P3 intervention & 71,04 & 7,55 & 1,42 & 4,13 & 0,12 & 1,26 & 3,52 & 0,13 & 0,58 & 1,78 & 0,19 & 1,45 & 4,26 & 0,15 \\
\hline P4 control & 36,75 & 8,34 & 0,49 & 1,63 & 0,25 & 0,84 & 2,31 & 0,25 & $-0,47$ & 0,63 & 0,37 & 1,31 & 3,69 & 0,22 \\
\hline $\begin{array}{l}\text { P4 intervention } \\
\text { Random part }\end{array}$ & 67,22 & 8,23 & 1,27 & 3,56 & 0,15 & 1,17 & 3,22 & 0,15 & 0,48 & 1,61 & 0,22 & 1,42 & 4,13 & 0,15 \\
\hline P1 control & 188,75 & 66,73 & 0,50 & 1,65 & 0,53 & 0,00 & 1,00 & 0,00 & 0,00 & 1,00 & 0,00 & 0,12 & 1,13 & 0,17 \\
\hline P1 intervention & 444,21 & 130,99 & 0,00 & 1,00 & 0,00 & 0,00 & 1,00 & 0,00 & 0,28 & 1,32 & 1,21 & 0,15 & 1,16 & 0,16 \\
\hline P2 control & 699,86 & 247,44 & 0,15 & 1,16 & 0,30 & 0,60 & 1,82 & 0,40 & 0,31 & 1,36 & 0,92 & 0,47 & 1,59 & 0,27 \\
\hline P2 intervention & 860,98 & 253,89 & 0,08 & 1,08 & 0,10 & 0,05 & 1,05 & 0,10 & 0,12 & 1,13 & 0,20 & 0,18 & 1,19 & 0,11 \\
\hline P3 control & 1049,87 & 371,19 & 0,22 & 1,24 & 0,27 & 0,42 & 1,52 & 0,29 & 0,59 & 1,80 & 0,72 & 0,44 & 1,55 & 0,25 \\
\hline P3 intervention & 1310,48 & 386,44 & 0,08 & 1,08 & 0,10 & 0,10 & 1,11 & 0,11 & 0,29 & 1,33 & 0,25 & 0,26 & 1,29 & 0,14 \\
\hline P4 control & 1112,19 & 393,22 & 0,37 & 1,45 & 0,35 & 0,54 & 1,72 & 0,34 & 0,60 & 1,82 & 0,78 & 0,50 & 1,65 & 0,27 \\
\hline P4 intervention & 1558,00 & 459,43 & 0,22 & 1,24 & 0,15 & 0,18 & 1,19 & 0,14 & 0,45 & 1,56 & 0,32 & 0,29 & 1,34 & 0,16 \\
\hline \multicolumn{15}{|l|}{ Intervals \& tests } \\
\hline Fixed part & & $p$ & \multicolumn{2}{|l|}{$\chi^{2}$} & $p$ & $\chi 2$ & \multicolumn{2}{|c|}{$p$} & $\chi^{2}$ & $p$ & $\chi 2$ & \multicolumn{2}{|c|}{$p$} & $\chi^{2}$ \\
\hline \multicolumn{2}{|c|}{ P1: control vs. intervention } & 0,04 & 4,43 & & 0,04 & 4,16 & \multicolumn{2}{|c|}{0,18} & 1,80 & 0,19 & 1,73 & \multicolumn{2}{|c|}{0,82} & 0,05 \\
\hline
\end{tabular}


Table 2 (continued)

\begin{tabular}{|c|c|c|c|c|c|c|c|c|c|c|}
\hline \multicolumn{11}{|l|}{ Intervals \& tests } \\
\hline Fixed part & $p$ & $\chi 2$ & $p$ & $\chi 2$ & $p$ & $\chi 2$ & $p$ & $\chi^{2}$ & $p$ & $\chi 2$ \\
\hline P2: control vs. intervention & 0,00 & 15,85 & 0,00 & 16,68 & 0,04 & 4,29 & 0,00 & 10,29 & 0,17 & 1,89 \\
\hline P3: control vs. intervention & 0,01 & 6,68 & 0,00 & 10,93 & 0,19 & 1,73 & 0,02 & 5,52 & 0,53 & 0,40 \\
\hline P4: control vs. intervention & 0,01 & 6,76 & 0,01 & 7,40 & 0,25 & 1,33 & 0,03 & 4,86 & 0,67 & 0,18 \\
\hline P1-P2: control vs. intervention & 0,00 & 15,17 & 0,18 & 1,78 & 0,88 & 0,02 & 1,00 & 0,00 & 0,00 & 8,57 \\
\hline P1-P3: control vs. intervention & 0,04 & 4,38 & 0,63 & 0,23 & 0,69 & 0,16 & 0,68 & 0,17 & 0,18 & 1,81 \\
\hline P1-P4: control vs. intervention & 0,04 & 4,40 & 0,76 & 0,10 & 0,68 & 0,17 & 0,68 & 0,17 & 0,33 & 0,96 \\
\hline P2-P3: control vs. intervention & 0,20 & 1,64 & 0,05 & 3,94 & 0,01 & 6,36 & 0,01 & 7,81 & 0,03 & 4,99 \\
\hline P3-P4: control vs. intervention & 0,62 & 0,25 & 0,68 & 0,17 & 0,88 & 0,02 & 0,95 & 0,00 & 0,49 & 0,47 \\
\hline P2-P4: control vs. intervention & 0,35 & 0,87 & 0,08 & 3,02 & 0,01 & 6,02 & 0,01 & 6,34 & 0,05 & 3,90 \\
\hline \multicolumn{11}{|l|}{ Random part } \\
\hline P1: control vs. intervention & 0,08 & 3,02 & 0,35 & 0,89 & n.a.b & n.a.b & 0,01 & 6,76 & 0,90 & 0,02 \\
\hline P2: control vs. intervention & 0,65 & 0,21 & 0,83 & 0,05 & 0,18 & 1,80 & 0,01 & 6,37 & 0,32 & 1,00 \\
\hline P3: control vs. intervention & 0,63 & 0,24 & 0,64 & 0,23 & 0,31 & 1,05 & 0,05 & 4,00 & 0,52 & 0,41 \\
\hline P4: control vs. intervention & 0,46 & 0,54 & 0,68 & 0,17 & 0,33 & 0,96 & 0,00 & 11,50 & 0,50 & 0,46 \\
\hline P1-P2: control vs. intervention & 0,76 & 0,10 & 0,32 & 0,98 & 0,18 & 1,80 & 0,03 & 4,76 & 0,12 & 2,41 \\
\hline P1-P3: control vs. intervention & 1,00 & 0,00 & 0,41 & 0,68 & 0,31 & 1,05 & 0,08 & 3,03 & 0,34 & 0,92 \\
\hline P1-P4: control vs. intervention & 0,73 & 0,12 & 0,47 & 0,52 & 0,33 & 0,96 & 0,00 & 9,65 & 0,33 & 0,93 \\
\hline P2-P3: control vs. intervention & 0,79 & 0,07 & 0,69 & 0,16 & 0,25 & 1,30 & 0,86 & 0,03 & 0,38 & 0,78 \\
\hline P3-P4: control vs. intervention & 0,49 & 0,48 & 0,91 & 0,01 & 0,75 & 0,10 & 0,06 & 3,54 & 0,81 & 0,06 \\
\hline P2-P4: control vs. intervention & 0,14 & 2,20 & 0,73 & 0,12 & 0,37 & 0,82 & 0,03 & 4,79 & 0,67 & 0,18 \\
\hline
\end{tabular}

Table 3

Results of the multilevel analyses for network content (ego-level).

\begin{tabular}{|c|c|c|c|c|c|c|c|c|}
\hline \multirow[t]{2}{*}{ Fixed part } & \multicolumn{2}{|l|}{ Solutions } & \multicolumn{2}{|c|}{ Meta-knowledge } & \multicolumn{2}{|c|}{ Problem reformulation } & \multicolumn{2}{|l|}{ Validation } \\
\hline & estimate & $S E$ & estimate & $S E$ & estimate & $S E$ & estimate & $S E$ \\
\hline P1 control & 13,31 & 1,74 & 11,19 & 1,54 & 12,88 & 1,84 & 11,31 & 1,63 \\
\hline P1 intervention & 22,00 & 2,34 & 19,22 & 2,42 & 20,52 & 2,31 & 19,35 & 2,15 \\
\hline P2 control & 17,19 & 2,69 & 13,44 & 2,05 & 17,25 & 2,59 & 16,63 & 2,77 \\
\hline P2 intervention & 36,96 & 3,23 & 31,87 & 3,01 & 33,78 & 3,10 & 33,48 & 3,29 \\
\hline P3 control & 19,81 & 3,19 & 16,13 & 2,43 & 19,88 & 3,24 & 19,06 & 3,10 \\
\hline P3 intervention & 37,22 & 4,38 & 32,39 & 3,83 & 33,87 & 4,07 & 34,26 & 4,13 \\
\hline P4 control & 17,31 & 3,23 & 13,38 & 2,60 & 16,75 & 3,17 & 16,38 & 3,12 \\
\hline P4 intervention & 33,52 & 4,26 & 29,39 & 3,91 & 30,87 & 4,05 & 30,78 & 3,86 \\
\hline \multicolumn{9}{|l|}{ Random part } \\
\hline P1 control & 48,47 & 17,14 & 38,15 & 13,49 & 54,11 & 19,13 & 42,47 & 15,01 \\
\hline P1 intervention & 126,09 & 37,18 & 134,95 & 39,80 & 122,86 & 36,23 & 106,23 & 31,33 \\
\hline P2 control & 115,65 & 40,89 & 67,25 & 23,78 & 106,94 & 37,81 & 122,36 & 43,26 \\
\hline P2 intervention & 240,30 & 70,86 & 208,37 & 61,45 & 220,78 & 65,10 & 249,29 & 73,51 \\
\hline P3 control & 163,15 & 57,68 & 94,73 & 33,49 & 168,36 & 59,52 & 153,43 & 54,25 \\
\hline P3 intervention & 440,60 & 129,93 & 336,85 & 99,33 & 380,11 & 112,09 & 392,37 & 115,70 \\
\hline P4 control & 166,47 & 58,85 & 107,86 & 38,13 & 160,81 & 56,86 & 155,61 & 55,02 \\
\hline P4 intervention & 417,03 & 122,98 & 350,85 & 103,46 & 376,72 & 111,09 & 342,95 & 101,13 \\
\hline \multicolumn{9}{|l|}{ Intervals \& tests } \\
\hline Fixed part & $p$ & $\chi 2$ & $p$ & $\chi 2$ & $p$ & $\chi^{2}$ & $p$ & $\chi^{2}$ \\
\hline P1: control vs. intervention & 0,00 & 8,87 & 0,01 & 7,81 & 0,01 & 6,70 & 0,00 & 8,88 \\
\hline P2: control vs. intervention & 0,00 & 22,11 & 0,00 & 25,62 & 0,00 & 16,79 & 0,00 & 15,36 \\
\hline P3: control vs. intervention & 0,00 & 10,32 & 0,00 & 12,87 & 0,01 & 7,24 & 0,00 & 8,67 \\
\hline P4: control vs. intervention & 0,00 & 9,21 & 0,00 & 11,66 & 0,01 & 7,54 & 0,00 & 8,43 \\
\hline P1-P2: control vs. intervention & 0,00 & 13,34 & 0,00 & 12,76 & 0,00 & 10,88 & 0,01 & 7,52 \\
\hline P1-P3: control vs. intervention & 0,04 & 4,32 & 0,02 & 5,57 & 0,10 & 2,77 & 0,08 & 3,13 \\
\hline P1-P4: control vs. intervention & 0,09 & 2,95 & 0,05 & 3,86 & 0,11 & 2,58 & 0,13 & 2,29 \\
\hline P2-P3: control vs. intervention & 0,36 & 0,83 & 0,35 & 0,89 & 0,29 & 1,12 & 0,52 & 0,41 \\
\hline P3-P4: control vs. intervention & 0,58 & 0,31 & 0,90 & 0,02 & 0,95 & 0,00 & 0,71 & 0,14 \\
\hline P2-P4: control vs. intervention & 0,23 & 1,43 & 0,35 & 0,86 & 0,32 & 0,99 & 0,38 & 0,77 \\
\hline \multicolumn{9}{|l|}{ Random part } \\
\hline P1: control vs. intervention & 0,06 & 3,60 & 0,02 & 5,31 & 0,09 & 2,82 & 0,07 & 3,37 \\
\hline P2: control vs. intervention & 0,13 & 2,32 & 0,03 & 4,59 & 0,13 & 2,29 & 0,14 & 2,22 \\
\hline P3: control vs. intervention & 0,05 & 3,81 & 0,02 & 5,34 & 0,10 & 2,78 & 0,06 & 3,50 \\
\hline P4: control vs. intervention & 0,07 & 3,38 & 0,03 & 4,86 & 0,08 & 2,99 & 0,10 & 2,65 \\
\hline P1-P2: control vs. intervention & 0,53 & 0,40 & 0,50 & 0,46 & 0,49 & 0,47 & 0,42 & 0,64 \\
\hline P1-P3: control vs. intervention & 0,13 & 2,25 & 0,14 & 2,19 & 0,22 & 1,52 & 0,15 & 2,11 \\
\hline P1-P4: control vs. intervention & 0,19 & 1,74 & 0,18 & 1,79 & 0,21 & 1,56 & 0,27 & 1,22 \\
\hline P2-P3: control vs. intervention & 0,11 & 2,55 & 0,16 & 2,00 & 0,23 & 1,44 & 0,20 & 1,63 \\
\hline P3-P4: control vs. intervention & 0,73 & 0,12 & 1,00 & 0,00 & 0,95 & 0,00 & 0,47 & 0,52 \\
\hline P2-P4: control vs. intervention & 0,22 & 1,49 & 0,21 & 1,59 & 0,22 & 1,53 & 0,49 & 0,48 \\
\hline
\end{tabular}


Table 4

Results of the multilevel analyses for network content (tie-level).

\begin{tabular}{|c|c|c|c|c|c|c|c|c|c|c|}
\hline \multirow[t]{2}{*}{ Fixed part } & \multicolumn{2}{|l|}{ Solutions } & \multicolumn{2}{|c|}{ Meta-knowledge } & \multicolumn{2}{|c|}{$\begin{array}{l}\text { Problem } \\
\text { reformulation }\end{array}$} & \multicolumn{2}{|l|}{ Validation } & \multicolumn{2}{|c|}{ Talk PD program } \\
\hline & estimate & $S E$ & estimate & $S E$ & estimate & $S E$ & estimate & $S E$ & estimate & $S E$ \\
\hline P1 control & 2,99 & 0,14 & 2,59 & 0,14 & 2,91 & 0,13 & 2,46 & 0,16 & n.a. & n.a. \\
\hline P1 intervention & 3,01 & 0,11 & 2,59 & 0,14 & 2,83 & 0,12 & 2,61 & 0,13 & n.a. & n.a. \\
\hline P2 control & 2,66 & 0,10 & 2,15 & 0,13 & 2,73 & 0,14 & 2,57 & 0,16 & 2,57 & 0,21 \\
\hline P2 intervention & 2,72 & 0,10 & 2,34 & 0,10 & 2,49 & 0,09 & 2,44 & 0,10 & 2,50 & 0,10 \\
\hline P3 control & 2,71 & 0,11 & 2,33 & 0,16 & 2,77 & 0,17 & 2,66 & 0,20 & 2,48 & 0,13 \\
\hline P3 intervention & 2,73 & 0,11 & 2,41 & 0,10 & 2,50 & 0,11 & 2,52 & 0,11 & 2,75 & 0,07 \\
\hline P4 control & 2,67 & 0,14 & 2,09 & 0,16 & 2,57 & 0,13 & 2,50 & 0,18 & 2,33 & 0,17 \\
\hline P4 intervention & 2,67 & 0,16 & 2,37 & 0,15 & 2,44 & 0,15 & 2,48 & 0,15 & 2,52 & 0,10 \\
\hline \multicolumn{11}{|l|}{ Random part - ego } \\
\hline P1 control & 0,01 & 0,09 & 0,00 & 0,00 & 0,00 & 0,00 & 0,08 & 0,12 & n.a. & n.a. \\
\hline P1 intervention & 0,11 & 0,08 & 0,28 & 0,13 & 0,13 & 0,09 & 0,20 & 0,11 & n.a. & n.a. \\
\hline P2 control & 0,00 & 0,00 & 0,08 & 0,08 & 0,14 & 0,09 & 0,24 & 0,14 & 0,53 & 0,24 \\
\hline P2 intervention & 0,12 & 0,06 & 0,14 & 0,06 & 0,09 & 0,05 & 0,12 & 0,06 & 0,12 & 0,05 \\
\hline P3 control & 0,06 & 0,06 & 0,25 & 0,14 & 0,28 & 0,14 & 0,37 & 0,20 & 0,11 & 0,08 \\
\hline P3 intervention & 0,18 & 0,08 & 0,12 & 0,06 & 0,14 & 0,07 & 0,16 & 0,07 & 0,00 & 0,00 \\
\hline P4 control & 0,12 & 0,08 & 0,24 & 0,14 & 0,10 & 0,08 & 0,32 & 0,16 & 0,30 & 0,15 \\
\hline P4 intervention & 0,44 & 0,16 & 0,38 & 0,14 & 0,36 & 0,14 & 0,37 & 0,14 & 0,11 & 0,05 \\
\hline \multicolumn{11}{|l|}{ Random part - tie } \\
\hline P1 control & 1,41 & 0,25 & 1,43 & 0,24 & 1,46 & 0,24 & 1,66 & 0,29 & n.a. & n.a. \\
\hline P1 intervention & 1,33 & 0,16 & 1,16 & 0,14 & 1,46 & 0,17 & 1,39 & 0,16 & n.a. & n.a. \\
\hline P2 control & 1,07 & 0,15 & 0,56 & 0,16 & 0,95 & 0,14 & 1,11 & 0,16 & 1,00 & 0,15 \\
\hline P2 intervention & 1,39 & 0,11 & 1,03 & 0,15 & 1,43 & 0,12 & 1,37 & 0,11 & 1,37 & 0,11 \\
\hline P3 control & 0,96 & 0,13 & 0,40 & 0,09 & 0,88 & 0,12 & 1,40 & 0,19 & 0,95 & 0,13 \\
\hline P3 intervention & 1,25 & 0,10 & 1,08 & 0,09 & 1,31 & 0,11 & 1,21 & 0,10 & 1,58 & 0,13 \\
\hline P4 control & 0,94 & 0,14 & 0,10 & 0,15 & 0,78 & 0,12 & 0,79 & 0,12 & 0,79 & 0,12 \\
\hline P4 intervention & 1,23 & 0,11 & 0,24 & 0,11 & 1,34 & 0,12 & 1,10 & 0,10 & 1,19 & 0,10 \\
\hline \multicolumn{11}{|l|}{ Intervals \& tests } \\
\hline Fixed part & $p$ & $\chi^{2}$ & $p$ & $\chi^{2}$ & $p$ & $\chi^{2}$ & $p$ & $\chi^{2}$ & $p$ & $\chi^{2}$ \\
\hline P1: control vs. intervention & 0,89 & 0,02 & 0,96 & 0,00 & 0,65 & 0,21 & 0,47 & 0,52 & n.a. & n.a. \\
\hline P2: control vs. intervention & 0,70 & 0,15 & 0,22 & 1,51 & 0,14 & 2,15 & 0,50 & 0,47 & 0,76 & 0,09 \\
\hline P3: control vs. intervention & 0,92 & 0,01 & 0,64 & 0,21 & 0,17 & 1,84 & 0,53 & 0,40 & 0,07 & 3,40 \\
\hline P4: control vs. intervention & 1,00 & 0,00 & 0,20 & 1,64 & 0,52 & 0,42 & 0,92 & 0,01 & 0,33 & 0,94 \\
\hline P1-P2: control vs. intervention & 0,87 & 0,03 & 0,37 & 0,81 & 0,43 & 0,62 & 0,25 & 1,30 & n.a. & n.a. \\
\hline P1-P3: control vs. intervention & 0,97 & 0,00 & 0,72 & 0,13 & 0,45 & 0,56 & 0,30 & 1,09 & n.a. & n.a. \\
\hline P1-P4: control vs. intervention & 0,94 & 0,01 & 0,31 & 1,03 & 0,86 & 0,03 & 0,55 & 0,35 & n.a. & n.a. \\
\hline P2-P3: control vs. intervention & 0,82 & 0,05 & 0,64 & 0,23 & 0,92 & 0,01 & 0,96 & 0,00 & 0,17 & 1,86 \\
\hline P3-P4: control vs. intervention & 0,96 & 0,00 & 0,48 & 0,50 & 0,58 & 0,31 & 0,69 & 0,16 & 0,73 & 0,12 \\
\hline P2-P4: control vs. intervention & 0,82 & 0,05 & 0,74 & 0,11 & 0,61 & 0,25 & 0,70 & 0,15 & 0,35 & 0,86 \\
\hline \multicolumn{11}{|l|}{ Random part - ego } \\
\hline P1: control vs. intervention & 0,40 & 0,70 & 0,03 & 4,52 & 0,16 & 1,99 & 0,46 & 0,56 & n.a. & n.a. \\
\hline P2: control vs. intervention & 0,04 & 4,06 & 0,55 & 0,35 & 0,64 & 0,22 & 0,43 & 0,63 & 0,11 & 2,61 \\
\hline P3: control vs. intervention & 0,23 & 1,45 & 0,41 & 0,67 & 0,38 & 0,77 & 0,33 & 0,94 & 0,19 & 1,70 \\
\hline P4: control vs. intervention & 0,07 & 3,17 & 0,45 & 0,57 & 0,10 & 2,66 & 0,80 & 0,07 & 0,24 & 1,40 \\
\hline P1-P2: control vs. intervention & 0,86 & 0,03 & 0,18 & 1,76 & 0,20 & 1,63 & 0,29 & 1,12 & n.a. & n.a. \\
\hline P1-P3: control vs. intervention & 0,93 & 0,01 & 0,04 & 4,09 & 0,14 & 2,15 & 0,23 & 1,47 & n.a. & n.a. \\
\hline P1-P4: control vs. intervention & 0,31 & 1,02 & 0,56 & 0,33 & 0,49 & 0,48 & 0,80 & 0,06 & n.a. & n.a. \\
\hline P2-P3: control vs. intervention & 0,93 & 0,01 & 0,31 & 1,02 & 0,64 & 0,22 & 0,74 & 0,11 & 0,27 & 1,24 \\
\hline P3-P4: control vs. intervention & 0,31 & 1,02 & 0,27 & 1,21 & 0,08 & 3,10 & 0,39 & 0,75 & 0,65 & 0,20 \\
\hline P2-P4: control vs. intervention & 0,31 & 1,05 & 0,69 & 0,16 & 0,11 & 2,59 & 0,50 & 0,45 & 0,48 & 0,50 \\
\hline \multicolumn{11}{|l|}{ Random part - tie } \\
\hline P1: control vs. intervention & 0,80 & 0,06 & 0,33 & 0,94 & 1,00 & 0,00 & 0,40 & 0,70 & n.a. & n.a. \\
\hline P2: control vs. intervention & 0,09 & 2,87 & 0,77 & 0,09 & 0,01 & 7,02 & 0,19 & 1,72 & 0,05 & 3,83 \\
\hline P3: control vs. intervention & 0,09 & 2,92 & 0,19 & 1,68 & 0,01 & 6,74 & 0,39 & 0,75 & 0,00 & 12,06 \\
\hline P4: control vs. intervention & 0,09 & 2,81 & 0,54 & 0,38 & 0,00 & 11,46 & 0,04 & 4,19 & 0,01 & 6,71 \\
\hline P1-P2: control vs. intervention & 0,23 & 1,45 & 0,30 & 1,09 & 0,12 & 2,45 & 0,11 & 2,51 & n.a. & n.a. \\
\hline P1-P3: control vs. intervention & 0,26 & 1,25 & 0,14 & 2,21 & 0,19 & 1,70 & 0,81 & 0,06 & n.a. & n.a. \\
\hline P1-P4: control vs. intervention & 0,27 & 1,23 & 0,24 & 1,36 & 0,09 & 2,93 & 0,08 & 3,04 & n.a. & n.a. \\
\hline P2-P3: control vs. intervention & 0,88 & 0,02 & 0,50 & 0,45 & 0,79 & 0,07 & 0,09 & 2,96 & 0,23 & 1,46 \\
\hline P3-P4: control vs. intervention & 0,95 & 0,00 & 0,59 & 0,29 & 0,52 & 0,41 & 0,03 & 4,65 & 0,24 & 1,41 \\
\hline P2-P4: control vs. intervention & 0,91 & 0,01 & 0,85 & 0,04 & 0,74 & 0,11 & 0,84 & 0,04 & 0,86 & 0,03 \\
\hline
\end{tabular}

\section{References}

Avalos, B. (2011). Teacher professional development in teaching and teacher education over ten years. Teaching and Teacher Education, 27(1), 10-20. http:/ dx.doi.org/10.1016/j.tate.2010.08.007.

Baer, M., Evans, K., Oldham, G. R., \& Boasso, A. (2015). The social network side of individual innovation. Organizational Psychology Review, 5(3), 191-223. http:// dx.doi.org/10.1177/2041386614564105.
Baker-Doyle, K. J. (2011). The networked teacher: How new teachers build social networks for professional support. New York: Teachers College Press.

Baker-Doyle, K. J., \& Yoon, S. A. (2010). Making expertise transparent: Using technology to strengthen social networks in teacher professional development. In A. Daly (Ed.), Social network theory and educational change (pp. 115-126). Cambridge, Massachusetts: Harvard Education Press.

Bakkenes, I., De Brabander, C., \& Imants, J. (1999). Teacher isolation and communication network analysis in primary schools. Educational Administration 
Quarterly, 35(2), 166-202. http://dx.doi.org/10.1177/00131619921968518.

Baume, D. (2006). Towards the end of the last non-professions? International Journal for Academic Development, 11(1), 57-60. http://dx.doi.org/10.1080/ 13601440600579050.

Bellotti, E. (2014). Qualitative networks: Mixed methods in sociological research. London: Routledge.

Blume, B. D., Ford, J. K., Baldwin, T. T., \& Huang, J. L. (2010). Transfer of training: A meta-analytic review. Journal of Management, 36(4), 1065-1105. http:// dx.doi.org/10.1177/0149206309352880.

Borgatti, S. P., \& Cross, R. (2003). A relational view of information seeking and learning in social networks. Management Science, 49(4), 432-445.

Borgatti, S. P., Everett, M. G., \& Johnson, J. C. (2013). Analyzing social networks. Los Angeles: Sage.

Brown, J. S., \& Duguid, P. (1991). Organizational learning and communities-ofpractice: Toward a unified view of working, learning, and innovation. Organization Science, 2(1), 40-57. http://dx.doi.org/10.1287/orsc.2.1.40.

Burt, R. S. (1992). Structural holes: The social structure of competition. Cambridge, MA: Harvard University Press.

Burt, R. S., \& Ronchi, D. (2007). Teaching executives to see social capital: Results from a field experiment. Social Science Research, 36(3), 1156-1183. http:// dx.doi.org/10.1016/j.ssresearch.2006.09.005.

Carolan, B. V. (2014). Social network analysis and educational research: Theory, methods, and applications. Thousand Oaks, CA: SAGE Publications.

Coburn, C., Choi, L., \& Mata, W. (2010). I would go to her because her mind is math. Network formation in the context of a district-based mathematics reform. In A. J. Daly (Ed.), Social network theory and educational change (pp. 33-50). Cambridge: Harvard Education Press.

Coburn, C., \& Russell, J. L. (2008). District policy and teachers' social networks. Education Evaluation and Policy Analysis, 30(3), 203-235.

Cox, M. D. (2004). Introduction to faculty learning communities. New Directions for Teaching and Learning, 97, 5-23. http://dx.doi.org/10.1002/tl.129.

Crossley, N., Bellotti, E., Edwards, G., Everett, M. G., Koskinen, J., \& Tranmer, M. (2015). Social network analysis for ego-nets. London: SAGE Publications Ltd.

Cross, R., Singer, J., Colella, S., Thomas, R. J., \& Silverstone, Y. (2010). The organizational network fieldbook: Best practices, techniques, and exercises to drive organizational innovation and performance. San Francisco: Jossey-Bass.

Cross, R., \& Sproull, L. (2004). More than an answer: Information relationships for actionable knowledge. Organization Science, 15(4), 446-462.

Cross, R., \& Thomas, R. J. (2008). How top talent uses networks and where rising stars get trapped. Organizational Dynamics, 37(2), 165-180.

Cross, R., \& Thomas, R. J. (2009). Driving results through social networks: How top organizations leverage networks for performance and growth. San Francisco: Jossey-Bass.

Daly, A. J., \& Finnigan, K. S. (2011). The ebb and flow of social network ties between district leaders under high-stakes accountability. American Educational Research Journal, 48(1), 39-79.

Datnow, A. (2011). Collaboration and contrived collegiality: Revisiting Hargreaves in the age of accountability. Journal of Educational Change, 12(2), 147-158. http:// dx.doi.org/10.1007/s10833-011-9154-1.

Denicolo, P., \& Becker, L. (2013). Teaching in higher education. London: SAGE Publications, Limited.

Devlin, M., \& Samarawickrema, G. (2010). The criteria of effective teaching in a changing higher education context. Higher Education Research \& Development, 29(2), 111-124. http://dx.doi.org/10.1080/07294360903244398.

van Duijn, M. A. J., van Busschbach, J. T., \& Snijders, T. A. B. (1999). Multilevel analysis of personal networks as dependent variables. Social Networks, 21(2), 187-210. http://dx.doi.org/10.1016/S0378-8733(99)00009-X.

Everett, M., \& Borgatti, S. P. (2014). Networks containing negative ties. Social Networks, 38, 111-120.

Fox, J. (1997). Applied regression analysis, linear models, and related methods. Thousand Oaks: Sage Publications.

Fox, A., \& Wilson, E. (2015). Networking and the development of professionals: Beginning teachers building social capital. Teaching and Teacher Education, 47(0), 93-107. http://dx.doi.org/10.1016/j.tate.2014.12.004.

Gamoran, A., Gunter, R., \& Williams, T. (2005). Professional community by design: Building social capital through teacher professional development. In L. V. Hedges, \& B. Schneider (Eds.), The social organization of schooling (pp. 111-126). New York: Russell Sage Foundation.

Gerken, M., Beausaert, S., \& Segers, M. (2016). Working on professional development of faculty staff in higher education: Investigating the relationship between social informal learning activities and employability. Human Resource Development International, 19(2), 135-151. http://dx.doi.org/10.1080/ 13678868.2015.1116241.

Granovetter, M. (1973). The strength of weak ties. American Journal of Sociology, 78(6), 1360-1380.

Gruber, H., Lehtinen, E., Palonen, T., \& Degner, S. (2008). Persons in the shadow: Assessing the social context of high abilities. Psychology Science Quarterly, 50(2), 237-258.

Hatala, J.-P., \& Fleming, P. R. (2007). Making transfer climate visible: Utilizing social network analysis to facilitate transfer of training. Human Resource Development Review, 6(1), 33-63.

Hogan, B., Carrasco, J. A., \& Wellman, B. (2007). Visualizing personal networks: Working with participant-aided sociograms. Field Methods, 19(2), 116-144.

Kilduff, M., \& Krackhardt, D. (1994). Bringing the individual back in: A structural analysis of the internal market for reputation in organizations. The Academy of
Management Journal, 37(1), 87-108. http://dx.doi.org/10.2307/256771.

Kyndt, E., Gijbels, D., Grosemans, I., \& Donche, V. (2016). Teachers' everyday professional development: Mapping informal learning activities, antecedents and learning outcomes. Review of Educational Research, 86(4), 1111-1150.

Lieberman, A., \& Pointer Mace, D. H. (2008). Teacher learning: The key to educational reform. Journal of Teacher Education, 59(3), 226-234. http://dx.doi.org/ $10.1177 / 0022487108317020$.

Lin, N., Cook, K., \& Burt, R. S. (2001). Social capital theory and research. New Brunswick, NJ: Transaction Publishers.

Louis, K. S., \& Marks, H. M. (1998). Does professional community affect the classroom? Teachers' work and student experiences in restructuring schools American Journal of Education, 106(4), 532-575.

McFadyen, M. A., \& Cannella, A. A. (2004). Social capital and knowledge creation: Diminishing returns of the number and strength of exchange. The Academy of Management Journal, 47(5), 735-746. http://dx.doi.org/10.2307/20159615.

McLaughlin, M. W., \& Talbert, J. E. (2006). Building school-based teacher learning communities: Professional strategies to improve student achievement. New York: Teachers College Press.

McPherson, M., Smith-Lovin, L., \& Cook, J. M. (2001). Birds of a feather: Homophily in social networks. Annual Review of Sociology, 27, 415-444.

Mehra, A., Kilduff, M., \& Brass, D. J. (2001). The social networks of high and low selfmonitors: Implications for workplace performance. Administrative Science Quarterly, 46(1), 121-146. http://dx.doi.org/10.2307/2667127.

Moolenaar, N. M. (2012). A social network perspective on teacher collaboration in schools: Theory, methodology, and applications. American Journal of Education, 119(1), 7-39. http://dx.doi.org/10.1086/667715.

Moolenaar, N. M., Daly, A., Cornelissen, F., Liou, Y.-H., Caillier, S., Riordan, R., et al. (2014). Linked to innovation: Shaping an innovative climate through network intentionality and educators' social network position. Journal of Educationa Change, 15(2), 99-123. http://dx.doi.org/10.1007/s10833-014-9230-4.

Moses, A. S., Heestand Skinner, D., Hicks, E., \& O'Sullivan, P. (2009). Developing an educator network: The effect of a teaching scholars program in the health professions on networking and productivity. Teaching and Learning in Medicine, 21(3), 175-179.

Nardi, B. A., Whittaker, S., \& Schwarz, H. (2002). NetWORKers and their activity in intensional networks. Computer Supported Cooperative Work, 11(1), 205-242. http://dx.doi.org/10.1023/a:1015241914483.

Parise, S. (2007). Knowledge management and human resource development: An application in social network analysis methods. Advances in Developing Human Resources, 9(3), 359-383. http://dx.doi.org/10.1177/1523422307304106.

Parker, A., Halgin, D. S., \& Borgatti, S. P. (2016). Dynamics of social capital: Effects of performance feedback on network change. Organization Studies, 37(3), 375-397. http://dx.doi.org/10.1177/0170840615613371.

Penuel, W., Sun, M., Frank, K. A., \& Gallagher, H. A. (2012). Using social network analysis to study how collegial interactions can augment teacher learning from external professional development. American Journal of Education, 119(1), 103-136. http://dx.doi.org/10.1086/667756.

Pil, F. K., \& Leana, C. (2009). Applying organizational research to public school reform: The effects of teacher human and social capital on student performance. Academy of Management Journal, 52(6), 1101-1124. http://dx.doi.org/10.5465 amj.2009.47084647.

Pitts, V. M., \& Spillane, J. P. (2009). Using social network methods to study school leadership. International Journal of Research \& Method in Education, 32(2), 185-207. http://dx.doi.org/10.1080/17437270902946660.

Postareff, L., Lindblom-Ylänne, S., \& Nevgi, A. (2007). The effect of pedagogical training on teaching in higher education. Teaching and Teacher Education, 23(5), 557-571. http://dx.doi.org/10.1016/j.tate.2006.11.013.

Ramsden, P. (1998). Managing the effective university. Higher Education Research \& Development, 17(3), 347-370. http://dx.doi.org/10.1080/0729436980170307.

Rasbash, J., Steele, F., Browne, W. J., \& Goldstein, H. (2016). A user's guide to MLwiN, v2.36. Centre for Multilevel Modelling. University of Bristol.

Rienties, B., \& Kinchin, I. M. (2014). Understanding (in)formal learning in an academic development programme: A social network perspective. Teaching and Teacher Education, 39, 123-135.

Roxå, T., \& Mårtensson, K. (2009). Significant conversations and significant networks: Exploring the backstage of the teaching arena. Studies in Higher Education, 34(5), 547-559. http://dx.doi.org/10.1080/03075070802597200.

Saroyan, A., \& Trigwell, K. (2015). Higher education teachers' professional learning: Process and outcome. Studies In Educational Evaluation, 46, 92-101. http:/| dx.doi.org/10.1016/j.stueduc.2015.03.008.

Spillane, J. P., Hallett, T., \& Diamond, J. B. (2003). Forms of capital and the construction of leadership: Instructional leadership in urban elementary schools. Sociology of Education, 76(1), 1-17. http://dx.doi.org/10.2307/3090258.

Spillane, J. P., Kim, C. M., \& Frank, K. A. (2012). Instructional advice and information providing and receiving behavior in elementary schools: Exploring tie formation as a building block in social capital development. American Educational Research Journal, 49(6), 1112-1145. http://dx.doi.org/10.3102/ 0002831212459339.

Spillane, J. P., \& Shirrell, M. (2017). Breaking up isn't hard to do: Exploring the dissolution of teachers' and school leaders' work-related ties. Educational Administration Quarterly. http://dx.doi.org/10.1177/0013161X17696557, $0013161 X 17696557$.

Stes, A., Clement, M., \& Van Petegem, P. (2007). The effectiveness of a faculty training programme: Long-term and institutional impact. International Journal for Academic Development, 12(2), 99-109. http://dx.doi.org/10.1080/ 
13601440701604898.

Stewart, M. (2014). Making sense of a teaching programme for university academics: Exploring the longer-term effects. Teaching and Teacher Education, 38, 89-98. http://dx.doi.org/10.1016/j.tate.2013.11.006.

Thomson, K. E. (2015). Informal conversations about teaching and their relationship to a formal development program: Learning opportunities for novice and midcareer academics. International Journal for Academic Development, 20(2), 137-149. http://dx.doi.org/10.1080/1360144X.2015.1028066.

Tynjälä, P. (2008). Perspectives into learning at the workplace. Educational Research Review, 3, 130-154.

Uzzi, B., \& Dunlap, S. (2005). How to build your network. Harvard Business Review, 83(12), 53-60

Valente, T. W. (2012). Network interventions. Science, 337(6090), 49-53. http:// dx.doi.org/10.1126/science.1217330.

Van den Bossche, P., \& Segers, M. (2013). Transfer of training: Adding insight through social network analysis. Educational Research Review, 8, 37-47. http:/ dx.doi.org/10.1016/j.edurev.2012.08.002.

Van Waes, S., Van den Bossche, P., Moolenaar, N. M., De Maeyer, S., \& Van Petegem, P. (2015a). Know-who? Linking faculty's networks to stages of instructional development. Higher Education, 70(5), 807-826. http://dx.doi.org/ 10.1007/s10734-015-9868-8.

Van Waes, S., Van den Bossche, P., Moolenaar, N. M., Stes, A., \& Van Petegem, P. (2015b). Uncovering changes in university teachers' professional networks during instructional development. Studies in Educational Evaluation, 46, 11-28. http://dx.doi.org/10.1016/j.stueduc.2015.02.003.

Van Waes, S., Moolenaar, N. M., Daly, A. J., Heldens, H. H. P. F., Donche, V., Van Petegem, P., \& Van den Bossche, P. (2016). The networked instructor: The quality of networks in different stages of professional development. Teaching and Teacher Education, 59, 295-308. http://dx.doi.org/10.1016/j.tate.2016.05. 022.

Vangrieken, K., Dochy, F., Raes, E., \& Kyndt, E. (2015). Teacher collaboration: A systematic review. Educational Research Review, 15(0), 17-40. http://dx.doi.org/ 10.1016/j.edurev.2015.04.002

Wellman, B., \& Frank, K. (2001). Network capital in a multilevel world: Getting support from personal communities. In N. Lin, K. Cook, \& R. S. Burt (Eds.), Social capital: Theory and research. New Jersey: Transaction Publishers.

Wenger, E., McDermott, R., \& Snyder, W. (2002). Cultivating communities of practice: A guide to managing knowledge. Cambridge, USA: Harvard Business School Press. 